SOSTENIBILIDAD DE LA POLÍTICA CAMBIARIA EN ECONOMÍAS PEQUEÑAS

Alejandro Reynoso del Valle ${ }^{1}$

DOCUMENTO DE INVESTIGACIÓN No. 9501

JULIO, 1995

1 Banco de México. Las opiniones expresadas por el autor pueden no corresponder a las de la institución. El autor agradece al grupo de trabajo de la Dirección de Estudios Económicos. 


\title{
SOSTENIBILIDAD DE LA POLÍTICA CAMBIARIA EN ECONOMÍAS PEQUEÑAS
}

\author{
ALEJANDRO REYNOSO DEL VALLE
}

JULIO, 1995

\section{DOCUMENTO DE INVESTIGACIÓN No. 9501}

\section{RESUMEN}

Este trabajo de investigación tiene como propósito explorar el papel que juega la política monetaria en la sostenibilidad de un régimen cambiario de flotación dentro de ciertos límites de intervención. Con tal fin se busca conjuntar algunos resultados de la teoría de colapsos cambiarios y la de bandas para después hacer algunas consideraciones sobre el diseño de un esquema operativo que permita abatir la volatilidad de corto plazo de la paridad, sin que ello implique la acumulación de desequilibrios que eventualmente conduzcan a una devaluación abrupta de la moneda local. A lo largo del documento se sigue un método heurístico para resaltar las consecuencias tanto de tener bandas como credibilidad endógena así como de la selección de la función de reacción del Banco Central. 


\section{SOSTENIBILIDAD DE LA POLÍTICA CAMBIARIA EN ECONOMÍAS PEQUEÑAS}

\section{INTRODUCCIÓN}

Prácticamente sin distinción, las autoridades financieras de los países buscan inducir un comportamiento estable de sus principales variables nominales. En la medida en que sean exitosas en este propósito no sólo se logra abatir la especulación, sino que es posible dar certeza a los agentes económicos para sus decisiones de consumo, ahorro e inversión.

Para la consecución de este objetivo el diseño del régimen cambiario juega un papel central, siendo un tipo de cambio fijo en un contexto de mercados de bienes y factores flexible, probablemente la solución más adecuada para una economía pequeña toda vez que en estas circunstancias desaparece el costos componente de la incertidumbre cambiaria y de precios. Desafotunadamente, en la práctica es muy difícil sostener una paridad fija frente a ataques especulativos. Por esta razón, los países han tratado de encontrar soluciones intermedias en las que se tolere cierta variabilidad del tipo de cambio dentro de límites de intervención predeterminados. Sin embargo, aun en esta situación, el mayor margen de acción de la política cambiaria es insuficiente para absorber rápidos y masivos movimientos de capitales como los vistos en los últimos años.

Por su trascendencia, el tema de la sostenibilidad de los regímenes cambiarios ha ocupado un lugar importante en la discusión académica, especialmente desde el abandono del patrón cambio-dólar. Así, a partir de finales de los años setenta comenzaron a aparecer varios artículos cuyo énfasis se uso en explicar la forma en que una política de expansión del déficit fiscal o el crecimiento autónomo del crédito interno influyen sobre el momento y sobre la magnitud de los colapsos cambiarios, tomando como punto de referencia un régimen de paridad fija o de deslizamiento predeterminado (Krugman, 1979; Flood y Garber, 1984; ; Banco y Garber, 1986). A pesar de su importancia, el enfoque de estos primeros trabajos presenta ciertas limitaciones para entender la experiencia reciente toda vez que no se detiene a analizar los efectos de la interacción entre los bancos centrales y los participantes del mercado en episodios en los que, pudiendo haber finanzas públicas equilibradas y tras período de política monetaria prudente, se presenta una crisis de confianza que eventualmente conduce a una devaluación abrupta. 
Un esfuerzo por encontrar una respuesta aparece en modelos como el de Flood y Garber (1984b) y Obstfeld (1986), en los que se plantea como línea de argumentación la posibilidad de encontrar equilibrios múltiples en un entorno en el que el público observa una función de reacción de la autoridad monetaria contingente, entre otros factores, a las propias expectativas del público. No obstante la aportación de estos resultados, quedaría aun sin explorar la forma en que una misma regla -no contingente- para la política monetaria puede, en ciertos casos contribuir indefinidamente a la estabilidad de la paridad y de tasas de interés y, en otros, constituir un factor que dificulte el cumplimiento de un compromiso cambiario.

Poco después, con el uso más generalizado de un sistema de bandas cambiarias la literatura se reorientó a estudiar los efectos de éstas en el tipo de cambio observado cotidianamente en los mercados, jugando un papel central la credibilidad que el público concediera a dicha bandas (Krugman, 1988; Blackburn y Sola, 1993; Agénor et. Al., 1992). Los resultados fueron sin duda interesantes, no sólo por el hecho de incorporar técnicas matemáticas más refinadas, sino porque llamaron la atención sobre los efectos estabilizadores de los límites de intervención creíbles. Destaca la noción de que aun antes de tocar dichos límites, el tipo de cambio mostraría una menor volatilidad dentro de la banda de la que se observaría en dicho rango de haberse permitido una libre flotación.

El tema de la realineación de las bandas cambiarias ha sido formalizado por Bertola y Caballero (1992) y por Werner (1994) con adaptaciones al modelo básico de Krugman (1988) mediante la introducción de supuestos sobre los determinantes del desplazamiento de los límites de intervención (ver también Chen y Giovannini, 1993). El rango de opciones exploradas incluye cambios anticipados, aleatorios y determinados por una relación exógena entre la probabilidad de una realineación y la posición del tipo de cambio dentro de la banda, faltando por modelar de manera integrada las ideas de la literatura del tipo de cambio con bandas ajustables y los conceptos contenidos en la literatura de colapsos cambiarios.

No es sino recientemente que la discusión se ha iniciado en esta dirección tomando como referencia, en buena medida, los hechos estilizados de las dos crisis más conspicuas de los últimos años: las devaluaciones de la libra esterlina y del peso mexicano (Eichengreen et. Al., 1995). Ara ello, la atención se está poniendo más que en el análisis de las tendencias de mediano plazo de las principales variables fiscales y monetarias, o de preferencias a la Paridad del Poder de Compra para saber si el tipo de cambio real está sobre o sub-valuado, en los mecanismos institucionales a través de los cuales opera 
la política monetaria, tanto por su importancia como determinante de las expectativas del público, como por sus implicaciones sobre la capacidad que efectivamente tengan los bancos centrales para controlar su crédito primario.

Este trabajo de investigación tiene como propósito explorar el papel que juega la política monetaria en la sostenibilidad de un régimen cambiario de flotación dentro de ciertos límites de intervención. Con tal fin se busca conjuntar algunos resultados de la teoría de colapsos cambiarios y la de bandas para posteriormente plantear algunas consideraciones sobre el diseño de un esquema operativo que permita abatir la volatilidad de corto plazo de la paridad, sin que ello implique la acumulación de desequilibrios que eventualmente conduzcan a una devaluación abrupta de la moneda local. A lo largo del documento se sigue un método heurístico para resaltar, sobre todo, las consecuencias de tener bandas con credibilidad endógena así como de la selección de la función de reacción del Banco Central. Cabe prevenir al lector a no esperar encontrar resultados que vayan más allá de lo que los modelos más sencillos de macroeconomía abierta predice, ya que el énfasis de la exposición es más en el cómo suceden las cosas a través de los mecanismos de transmisión de la política monetaria que en los resultados mismos de estática comparativa.

El documento se ha dividido en 4 partes. La sección 2 hace una descripción de la experiencia mexicana de los últimos años a fin de aprovechar un caso concreto para identificar algunos hechos estilizados del colapsos de un régimen de bandas; la sección 3 presenta un modelo monetario de determinación del tipo de cambio que reproduce tales hechos estilizados y que se utiliza para ver el efecto que distintas combinaciones de parámetros tienen sobre la sostenibilidad de un régimen de bandas. La parte 4 ofrece las consideraciones finales.

\section{REFLEXIONES A PARTIR DE LA EXPERIENCIA INTERNACIONAL: EL CASO DE MÉXICO}

\subsection{DESCRIPCIÓN DE LOS ACONTECIMIENTOS}

Después de un largo proceso de estabilización y cambio estructural cuyos principales resultados eran alentadores, México enfrenta una seria crisis financiera que se inició con el colapso de su régimen cambiario en diciembre de 1994. 
La devaluación del peso mexicano llama la atención puesto que ocurrió en circunstancias en las que difícilmente puede afirmarse que existiera un desequilibrio importante en las finanzas públicas, o que la autoridad monetaria hubiese seguido de manera deliberada una política de expansión acelerada de la base monetaria. El análisis cuidadoso de los acontecimientos revela que, sin entrar por ahora en discusión sobre el mecanismo de transmisión, los factores que "detonaron" la crisis fueron esencialmente exógenos a la política económica.

Desde el punto de vista monetario, lo sucedido puede explicarse de manera sucinta con la ayuda de cinco gráficas. La primera muestra el régimen cambiario vigente en México desde el 11 de noviembre de 1991 hasta el 19 de diciembre de 1994. Se trata de una banda cuyo piso de intervención permaneció constante durante la vigencia del régimen, mientras que el techo se deslizó a razón de N\$0.0002 diarios hasta octubre de 1992, y N\$0.0004 por día en adelante. De acuerdo con estos parámetros acordados en las negociaciones del Pacto Económico, cuando se presentaban presiones devaluatorias contra el peso el tipo de cambio podía fluctuar hasta el techo de la banda, donde el Banco de México intervenía vendiendo reservas en el mercado. Por el contrario, las intervenciones en el piso de la banda correspondían a compras de divisas para detener la apreciación del peso. Estas últimas fueron generalmente esterilizadas para evitar los efectos inflacionarios de las entradas de capitales. Cabe apuntar que hasta noviembre de 1993 el Banco de México operaba una banda de intervención más estrecha que la "banda Pacto" y realineable. Este concepto se eliminó toda vez que las autoridades consideraron que las expectativas de los participantes en cuanto a las citadas realineaciones no contribuían a la estabilidad de la paridad (para más detalles ver Shwartz, 1994 y los Informes Anuales del Banco de México).

La participación del Banco de México en el mercado cambiario durante 1994 se ilustra en la gráfica 2, donde la línea más gruesa corresponde al monto de las intervenciones diarias del Instituto Emisor, y la línea delgada muestra el resultado acumulado de estas interve3nciones. Así, durante los primeros dos meses del año, y en buena medida como consecuencia de las expectativas favorables que siguieron a la entrada en vigor del Tratado Trilateral de Libre Comercio con Estados Unidos y Canadá, el Banco de México compró montos importantes de moneda extranjera, por lo que se acumularon cerca de 5.0 mil millones de dólares. En este período, el tipo de cambio se mantuvo muy cerca del límite inferior interno de intervención del Banco de México de N\$3.10 por dólar. 


\section{Gráfica 1}

Régimen Cambiario

Vigente desde el 11 de noviembre de 1991 hasta el 19 de noviembre de 1994

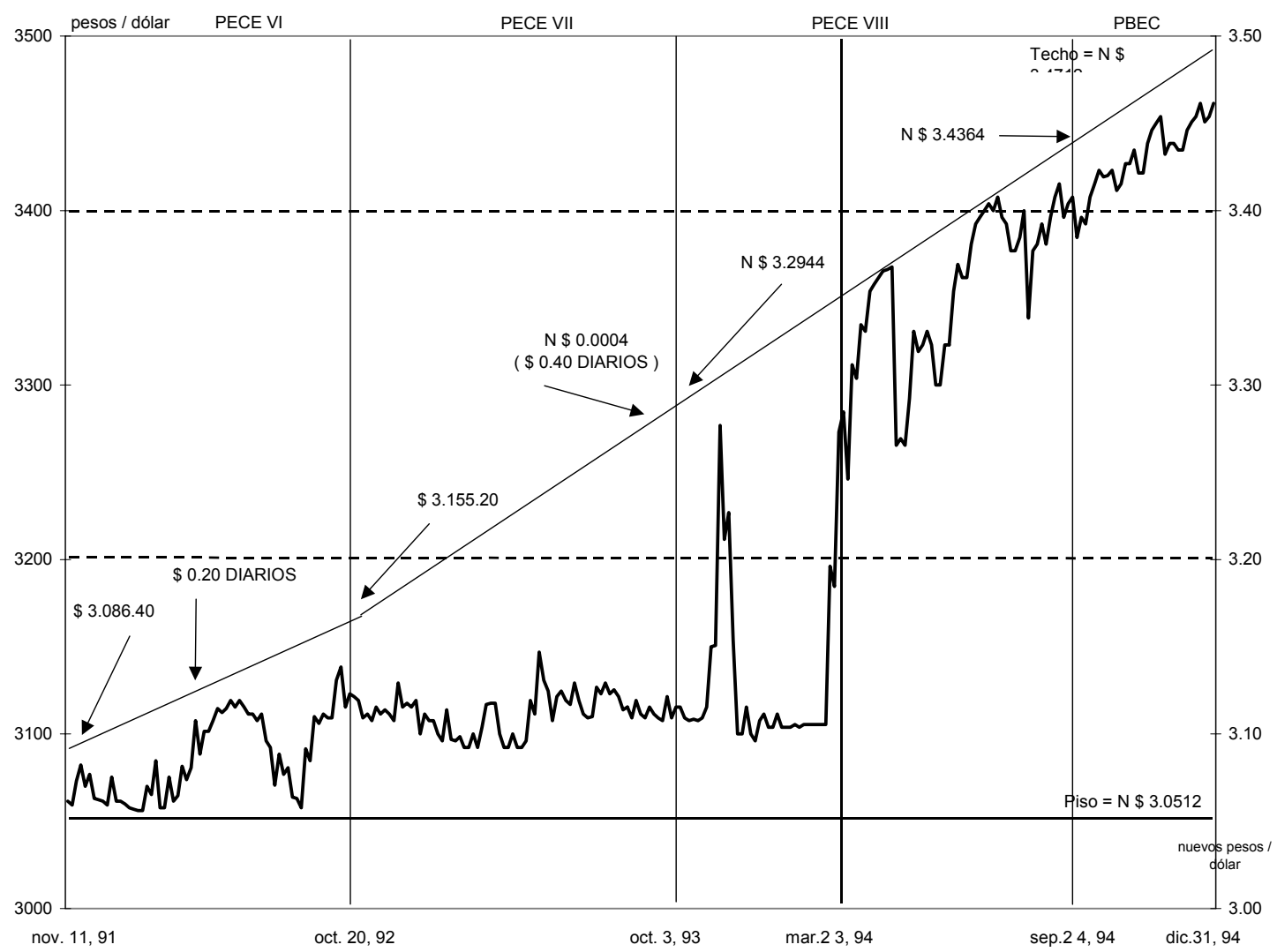

$\begin{aligned} \text { Nota: } & \text { Cabe recordar que a partir del } 1^{\circ} \text {. de enero de } 1993 \text { fue introducida una nueva unidad monetaria, el nuevo } \\ & \text { peso (N\$), cuya equivalencia con los pesos anteriores (\$) es de N\$1/ } \$ 1,000 . \\ & \text { Por PECE se hace referencia al Pacto para la Estabilidad, la Competitividad y el Empleo, acordado entre el } \\ & \text { Gobierno Federal, los sindicatos, las organizaciones campesinas y el sector empresarial. } \\ * & \text { Día natural } \\ & \text { Última observación } 19 \text { de diciembre de } 1994\end{aligned}$

Esta situación cambió a finales de marzo, siguiendo al ajuste del tipo de cambio provocado por las declaraciones políticas del entonces Comisionado para la Paz y Reconciliación en Chiapas, el asesinato del candidato presidencial del PRI, Luis Donaldo Colosio. Las consecuencias de este acontecimiento en la confianza del público inversionista fueron de gran seriedad, de tal suerte que, durante el mes inmediato siguiente, la pérdida de reservas internacionales superó los 10 mil millones de dólares. Por su parte, las autoridade4s respondieron, en la inteligencia de que situaciones como ésta eran de naturaleza no recurrente, utilizando los grados de libertad con que contaban y bajo el criterio de distribuir la carga del ajuste entre los instrumentos disponibles. De esta forma se combinaron tasas de interés más elevadas con sustitución de deuda pública denominada en pesos por deuda pagadera en 
pesos pero referida en dólares, y permitiendo que el tipo de cambio se desplaza hasta el límite superior de la banda acordada en el Pacto Social.

\section{Gráfica 2}

Intervención Diaria y Acumulada del Banco de México

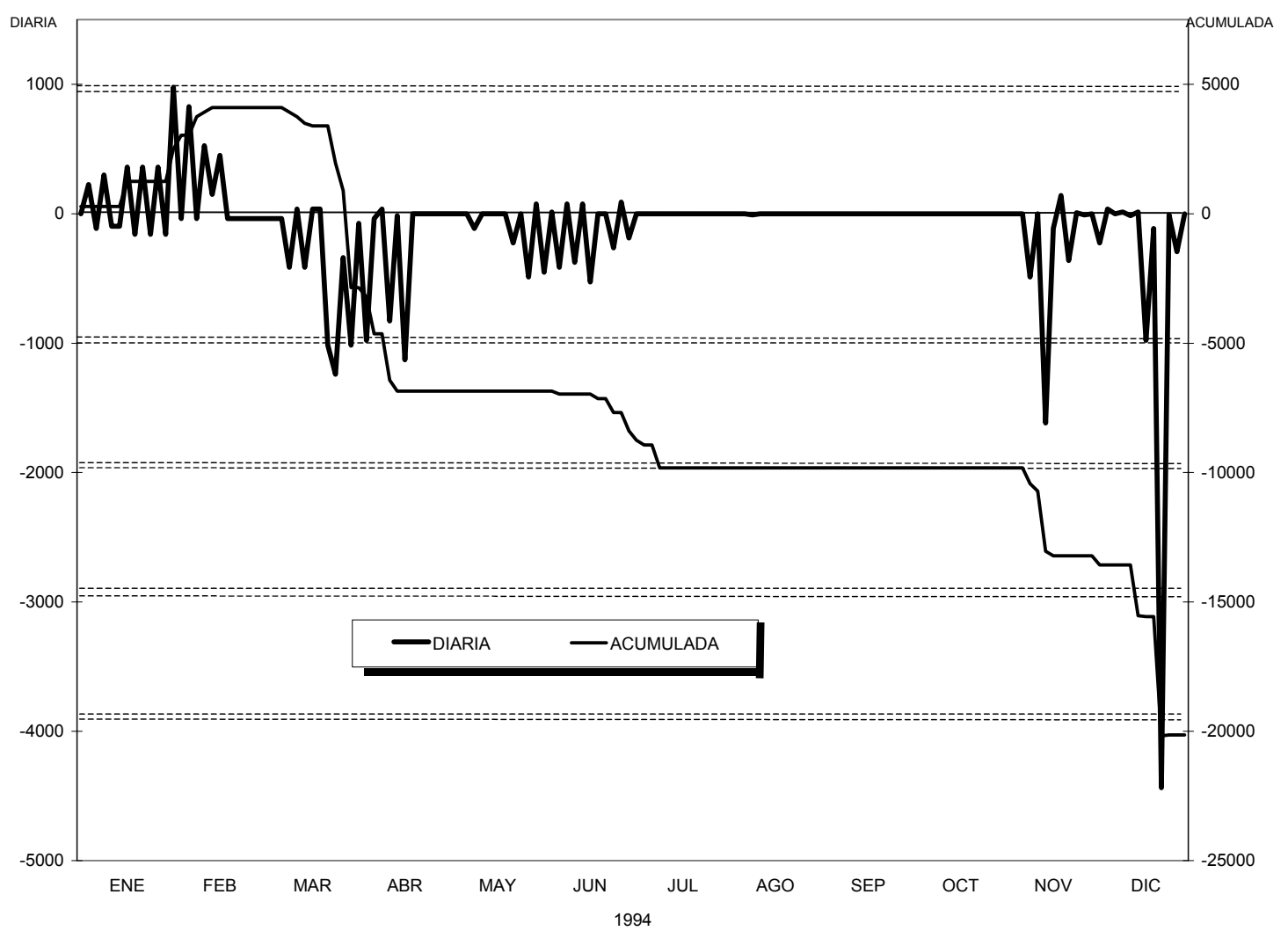

En retrospectiva podría decirse que las acciones adoptadas tuvieron éxito, toda vez que las intervenciones del Banco de México se detuvieron a partir de la tercera semana de abril. De hecho, la balanza de pagos retornó al equilibrio por poco más de dos meses, situación que nuevamente se interrumpió a raíz de la renuncia del Secretario de Gobernación, por cierto no aceptada por el Presidente de la República, a unas semanas de las elecciones presidenciales y para renovar el Congreso Federal. Entre junio y julio el Banco Central perdió cerca de 3.0 mil millones de dólares, restableciendo nuevamente el equilibrio de balanza de pagos durante el lapso de agosto a noviembre. Entonces, por tercera ocasión, eventos políticos se tradujeron en intranquilidad en los mercados a partir de acusaciones del Subprocurador General de la República en torno al asesinato de su hermano, Secretario General del PRI. Esta vez la pérdida de reservas fue de 3.7 mil millones de dólares. 


\section{Gráfica 3}

Saldos de la Reserva Internacional Neta 1994

(millones de dólares)

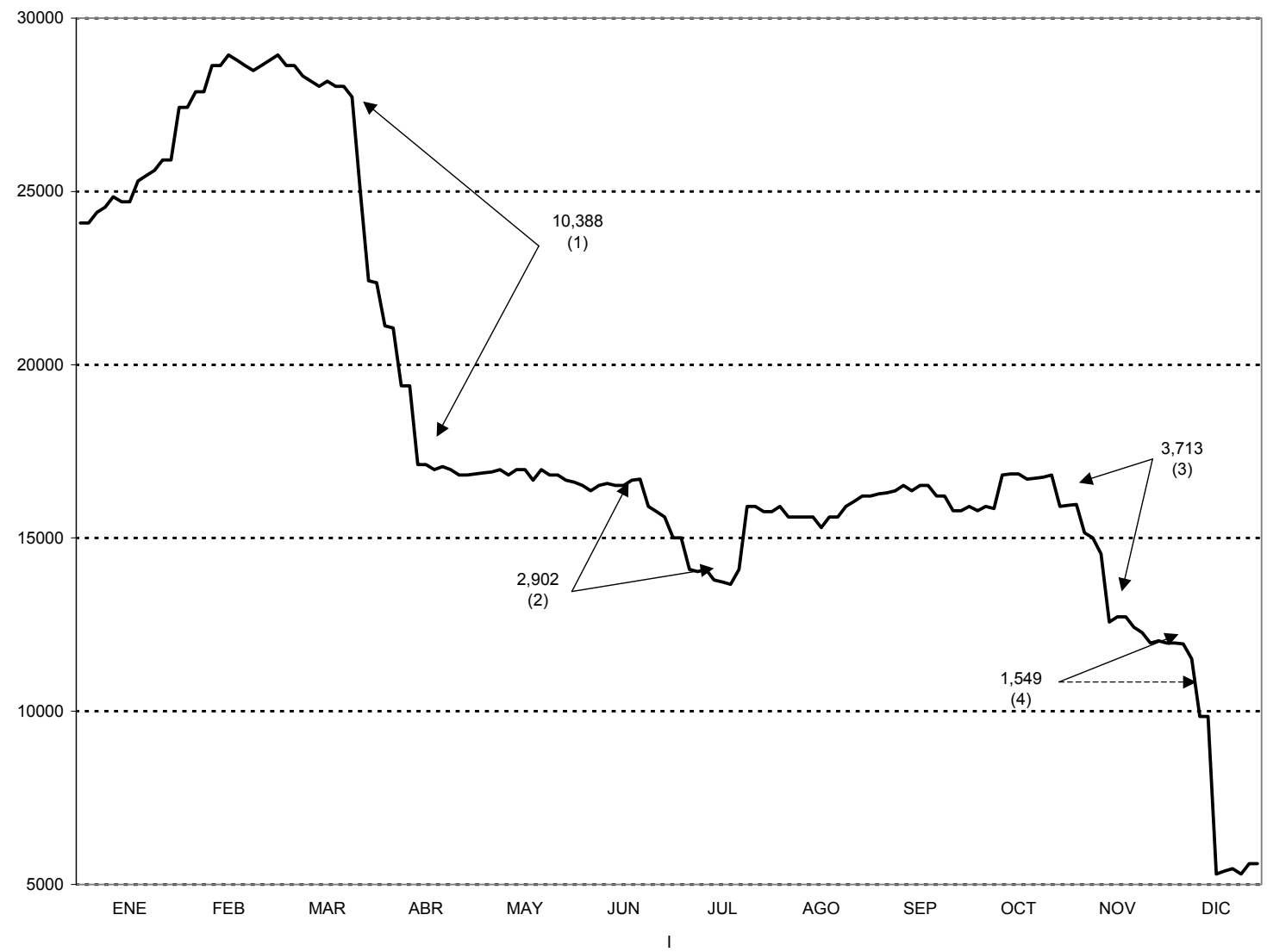
(1) Asesinato del candidato del PRI a la Presidencia
(3) Denuncias del Subprocurador
(2) Renuncia del Secretario de Gobernación
(4) Hostilidades intensificadas del EZLN
Fuente: Banco de México

La fase final de este proceso ocurrió cuando el Ejército Zapatista de Liberación Nacional inició una nueva movilización de fuerzas en la zona de conflicto de Chiapas, coincidiendo con el anuncio de las proyecciones oficiales de un cuantioso déficit en la cuenta corriente para $1995 \mathrm{y}$ el aumento en las tasas de interés por parte de las autoridades monetarias de los Estados Unidos. A partir de estos acontecimientos el Banco de México vio reducida su reserva neta a niveles tales que se tuvo que abandonar el régimen de bandas para dejar la cotización del peso a ser determinada libremente por las fuerzas del mercado.

El análisis del comportamiento de las tasas de interés y de los componentes de la base monetaria durante la fase de salidas de capitales ofrece un ángulo muy relevante de la experiencia mexicana. Por 
un lado es valido afirmar que las autoridades monetarias, dentro de las limitaciones que les imponía la debilidad del sistema financiero, persiguieron una política monetaria astringente. Ello puede argumentarse a partir de la evolución mostrada por las tasas de interés tanto nominales como en términos reales, así como el incremento significativo en la colocación de Tesobonos, que por su naturaleza incorporan una opción que puede interpretarse como una alternativa al incremento en las tasas de interés. Sin embargo, queda aún por ponderar qué importancia tuvieron estas restricciones operativas del Banco Central sobre el mecanismo de transmisión de los choques exógenos.

Para entender la importancia de este tema es preciso repasar algunas características de la operación cotidiana del Banco de México. Un primer elemento a destacar es el hecho de que desde 1991 dejó de operar en el país el requisito de encaje legal para los bancos comerciales por lo que, consecuentemente, las instituciones de crédito redujeron significativamente el monto de sus depósitos en el Banco de México ${ }^{1}$. Desde entonces, cuando en sus operaciones diarias los bancos registraban un aumento en la demanda por billetes y monedas por parte del público, contaban básicamente con dos opciones para atenderla. Ya sea acudiendo al mercado interbancario para obtener los recursos o bien incurriendo en un sobregiro, a un mayor costo, en su cuenta corriente en el Banco Central.

Mientras sólo algunos bancos se sobregiraran, las operaciones diarias podían ser compensadas entre los propios bancos participantes sin ningún problema, de manera que aumentos moderados en las tasas de interés permitían que el equilibrio se reestableciera en el mercado de dinero. Una situación distinta se presenta cuando la mayoría de las instituciones tenían sobregiros, y más que eso, cuando eran de gran magnitud. Esto debido a que, para que el ajuste fuera automático, se habrían requerido grandes cambios en las tasas de interés, trayendo consigo serias consecuencias sobre la salud financiera de los bancos. Por ello, en escenarios como éste, era indispensable la intervención de un prestamista de última instancia que proporcionara por plazos cortos la liquidez necesaria para que el sistema de pagos pudiera "cerrar".

Las dos gráficas siguientes resumen la manera en que las presiones sobre el merado de cambios se transmitieron al mercado de dinero. En relación al comportamiento de la base monetaria, la gráfica 4 permite ver cómo aquélla creció en 1994 prácticamente al mismo ritmo al que venía haciéndolo durante los años anteriores. Simultáneamente se observan cambios de importancia en la dinámica de los

El efecto que tuvo el abandono del encaje legal sobre la liquidez al adoptarse la medida fue totalmente esterilizado mediante operaciones de mercado abierto. 
conceptos que constituyen las fuentes de la base monetaria. La línea discontinua corresponde a las reservas internacionales, donde nuevamente se ven las caídas que siguieron a los acontecimientos políticos ya referidos, mientras que la línea delgada señala como la pérdida de liquidez que acompañó a los episodios de salidas de capital fue repuesta mediante crédito primario del Instituto Emisor a consecuencia; en buena medida, de las restricciones que imponía la operación del sistema de pagos y la vulnerabilidad del sistema bancario.

\section{Gráfica 4}

Base Monetaria y Crédito Interno Neto

(saldos nominales en miles de millones de nuevos pesos)

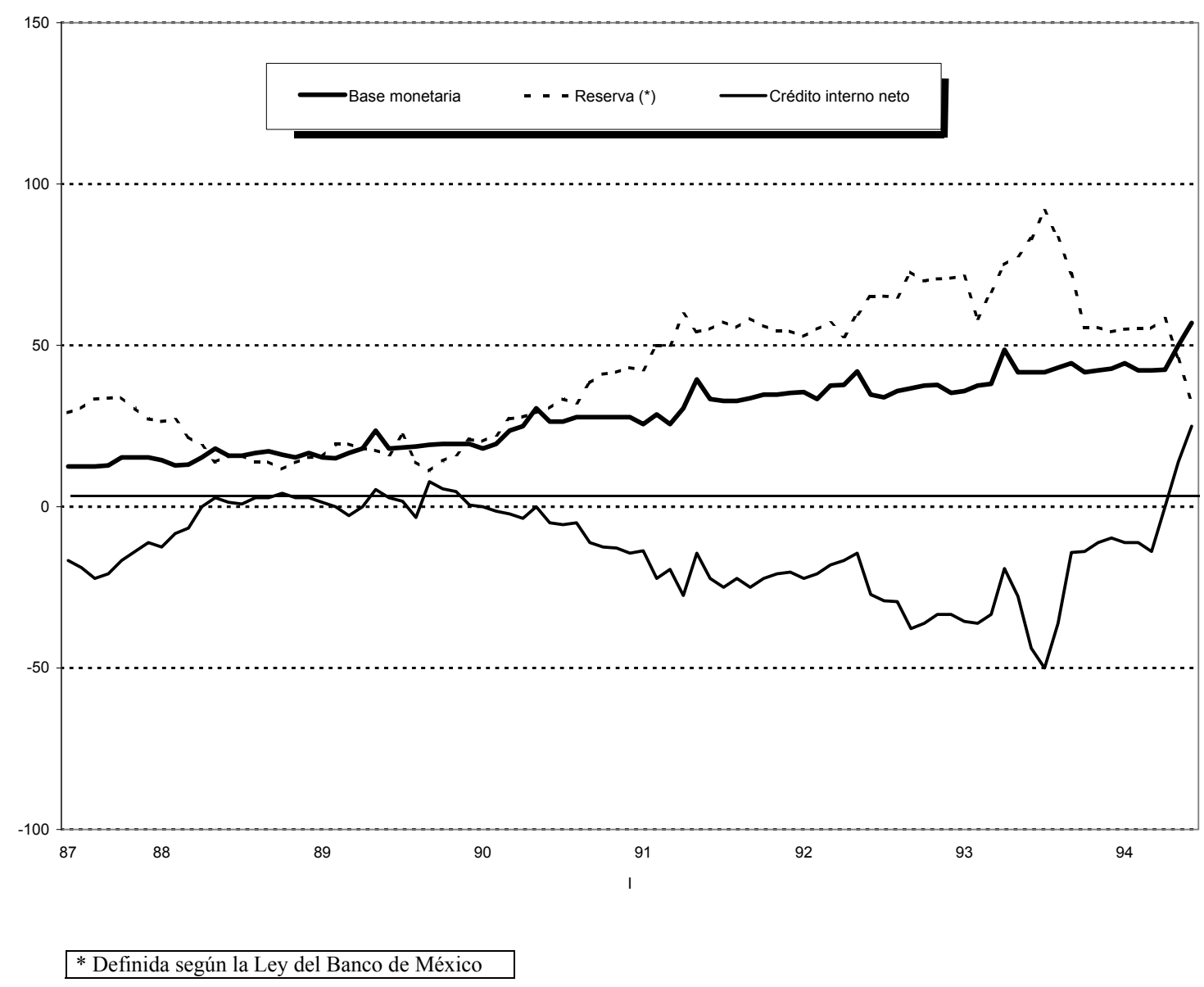

Si bien el Banco Central proporcionó toda la liquidez que requería el mercado en circunstancias de presión cambiaría, también es justo reconocer que lo hizo a tasas de interés muy elevadas. En la gráfica 5 se ve como a partir de marzo de 1994 las tasas interbancarias y la de intervención del Banco de México en el mercado matutino se incrementaron considerablemente, alcanzando niveles que en 
promedio superaron el 15\% real que, por cierto, de haber sido superiores hubiesen tenido efectos muy desfavorables sobre la situación financiera del sistema bancario. La forma en que esta mecánica de operación de la política monetaria afectaba la liquidez de largo plazo del sistema, parte del hecho de que al llevar la tasa del Banxico matutino a niveles elevados los bancos buscarían pagar los créditos recurriendo a fuentes alternativas menos costosas, como lo sería la captación directa en el propio mercado interbancario o en el extranjero. De esta manera, la expansión del crédito primario sería solamente transitoria toda vez que al superarse la situación que hizo que las instituciones de crédito recurrieran al Banco Central, éstas tendrían un fuerte incentivo para amortizar sus obligaciones en un breve lapso ya sea atrayendo recursos del exterior o mediante el abatimiento de la demanda por billetes y monedas.

\section{Gráfica 5}

Tasa de Cetes, Interbancaria y del Mercado Matutino

Enero - Diciembre 1994

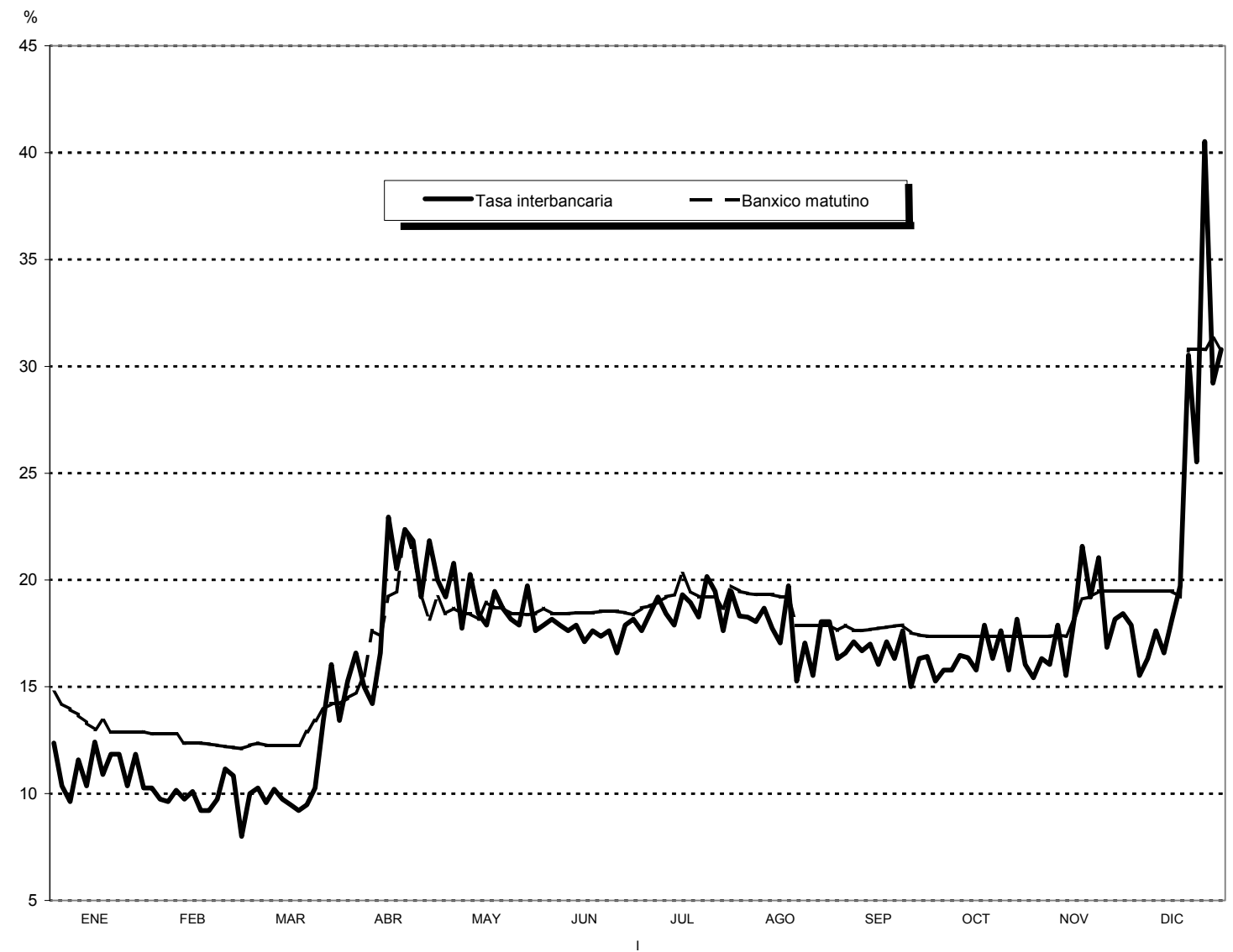

Fuente: Banco de México 
Ciertamente, en un marco de operaciones como el descrito, el propósito de controlar el crédito interno mediante variaciones en las tasas de interés a las que presta el Banco Central puede alcanzarse eficazmente cuando los choques que se enfrentan de lado de la demanda por dinero de base son no recurrentes. Sin embargo, el control del crédito primario se dificulta considerablemente cuando la magnitud de dichos cambios no anticipados es grande y si se presentan repentina y repetidamente. Esto fue lo que sucedió en México.

\subsection{LOS HECHOS ESTILIZADOS}

Es muy difícil simplificar fenómenos tan complejos como las crisis del peso mexicano. Más aún, a pesar de los numerosos reportes y opiniones que se han vertido al respecto no puede decirse que a la fecha se haya alcanzado un consenso entre analistas, autoridades y académicos sobre las causas, los tiempos y la magnitud de este importante hecho. Por esto mismo es prudente aclarar de antemano que este documento no intenta entrar en este debate sino únicamente aprovechar un caso concreto para identificar algunas características de la dinámica del colapso de los regímenes de bandas.

Así pues, y sin prejuicio de mencionar otros, en las siguientes secciones se busca presentar un marco de referencia congruente con los siguientes cuatro hechos estilizados.

a. Se tiene una economía cuya política monetaria se distingue por acomodar las necesidades de dinero de base que va señalando el mercado. En este ejemplo, la base monetaria creció a un ritmo más o menos constante durante un lapso de varios años. Durante la mayor parte del tiempo esta función de reacción del banco central parece haber sido plenamente compatible con un régimen cambiario de bandas, inclusive en presencia de choques desfavorables de naturaleza transitoria. Sin embargo, cuando se presentan eventos que implican pérdidas significativas de reservas, la misma regla monetaria resultó incompatible con el sostenimiento del compromiso cambiario.

Estas diferencias en el desempeño de una misma regla monetaria plantean la necesidad de entender mejor cuáles son las condiciones bajo las cuales se puede presentar uno u otro resultado. 
b. Se observa un comportamiento muy distinto de la dinámica del tipo de cambio dentro de la banda cuando hay abundantes reservas que cuando no es así.

En el primer caso, después de choques que pudieran haber acercado al paridad al techo de la banda, ésta regresaba hacia el centro de la misma siguiendo a eventos favorables. En el otro, tras un acontecimiento negativo el tipo de cambio parece "quedarse quieto" al techo de la banda aún después de buenas noticias tal y como fueron los resultados de las elecciones presidenciales.

c. Debido al sesgo del tipo de cambio hacia el techo de la banda cuando las reservas son escasas, acontecimientos negativos que podrían considerarse de menor importancia parecen tener efectos sustanciales en el mercado de cambios.

Por ejemplo, el asesinato del cardenal Posadas Ocampo en 1993 y el inicio de las hostilidades del EZLN en enero de 1994 no tuvieron las consecuencias en el mercado de cambios mostradas por otros sucesos comparables de violencia política tras la muerte del candidato presidencial del PRI.

d. Por último el hecho quizá más obvio, aunque no sobra mencionarlo, es que a diferencia de lo que apuntan los resultados básicos de la literatura de bancas creíbles la experiencia muestra que no siempre las intervenciones del Banco Central son pequeñas y no siempre los regímenes de bandas son sostenibles.

\section{UN MODELO MÍNIMO}

Se presenta aquí un modelo de determinación del tipo de cambio cuya especificación difiere de la literatura de bandas cambiarias principalmente en dos aspectos. Por un lado, se opta por trabajar en tiempo discreto orientando las conclusiones con resultados de simulaciones para distintos parámetros. Por otro lado, en vez de partir de la ecuación de paridad de tasas de interés, se plantea un esquema que toma al caso de perfecta integración de los mercados de capitales sólo como una situación particular considerando que pueden existir otras razones (costos de transacción para ahorradores pequeños o 
derivados de impuestos $\mathrm{u}$ otras medidas gubernamentales para prevenir la libre movilidad de capitales, requerimientos de liquidación adelantados - cash in advance constraints- o no neutralidad al riesgo de algunos inversionistas) por las cuales el público no intenten ajustar completamente la composición de sus portafolios ante pequeñas oportunidades de arbitraje del diferencial no cubierto de tasas.

En esta economía se tienen tres tipos de activos financieros: dinero, $M_{t}$; instrumentos de deuda gubernamental denominados en moneda nacional, $B_{t}$; que pagan una tasa de interés nominal $r_{t} ; \mathrm{y}$ dólares, cuyo rendimiento en términos de la moneda local está dado por la tasa de depreciación del tipo de cambio, $e_{t}+1-e_{t}$.

Para los propósitos de este ejercicio los dólares pueden estar ya sea en poder del Banco Central, formando parte de la reserva internacional, o en manos del público. El concepto que se define como demanda de dólares se refiere a las tenencias de éstos en poder del público. Se supone que el público puede pedir prestado en dólares para comprar instrumentos denominados en moneda nacional, o bien tomar posiciones largas en dólares como parte de sus tenencias. No se ponen límites explícitos al endeudamiento en moneda extranjera. Por su parte, no se considera la situación en la que el público pida prestado en moneda local en términos netos, de tal forma que el crédito primario del Banco Central corresponderá exclusivamente al que resulte de la sustitución de acreedor que deriva de las operaciones de mercado abierto.

La ecuación (1) se refiere a la relación que existe entre cambios en las posiciones netas del público y las reservas internacionales. Esto quiere decir que cuando el público se endeude en dólares esto se reflejará necesariamente en aumentos en las reservas del Banco Central. Por otro lado, si el público incrementa sus tenencias netas de dólares éstas provendrán de la reserva internacional del Banco Central según se describe más adelante.

$$
\begin{aligned}
& D^{s}{ }_{t}=D_{t-1}+\left(R_{t-1}-R_{t}\right) \\
& B_{0} \geq R_{0}=R \\
& R_{t} \geq 0 \forall t
\end{aligned}
$$

Por su parte, se considera que los participantes presentan una demanda por dólares que depende del nivel observado del tipo de cambio $e_{t}$, de las tasas de interés internas $r_{t}$, de la depreciación esperada 
tomando como base la información disponible en el periodo t-, $E_{t}\left[e_{t}+1\right]-e_{t}$, y de un choque aleatorio, en los términos de la ecuación (2). Como se dijo arriba se consideró conveniente trabajar con distintos grados de movilidad de capitales. Cuando el coeficiente $d_{2}$ toma valores elevados se tendrá una situación en la que los mercados de capitales están fuertemente integrados, por lo que las oportunidades que arbitraje son aprovechadas de manera inmediata y masiva. En contraste, valores pequeños de $d_{2}$ representan el caso donde las razones por las que el público mantiene dólares tienen predominantemente que ver, por ejemplo, con transacciones corrientes. También puede ser útil apuntar que si $d_{2}=d_{3}$ el tercer término de la ecuación (2) corresponde precisamente al diferencial no cubierto de tasas de interés.

$$
\begin{aligned}
& D^{d}{ }_{t}=d_{0}-d_{1} e_{t}+d_{2} E_{t}\left[e_{t}+1-e_{t}\right]-d_{3} r_{t}+\varepsilon_{t} \\
& \varepsilon_{t}=\varepsilon_{t-1}+u_{t} \\
& u_{t}-N\left(0, \sigma^{2}\right), \forall t \\
& D_{t} \in \mathfrak{R} \forall t
\end{aligned}
$$

La ecuación (3) es la definición de la base monetaria en términos de sus fuentes: crédito primario $C_{t}, \mathrm{y}$ activos internacionales $e+R_{t}$

$$
\begin{aligned}
& M^{s}{ }_{t}=C_{t}+e_{t} R_{t} \\
& M_{t} \geq 0 ; C_{t} \geq 0 \forall t
\end{aligned}
$$

La demanda por dinero de base está dada por la ecuación (4) en la que se observa un componente fijo, correspondiendo éste a los fines de transacción, y otro que responde principalmente al costo de oportunidad respecto de otros activos denominados en moneda local.

$$
M^{d}{ }_{t}=1_{0}-11 r_{t}
$$

Se supone que al inicio de cada período las personas tienen una dotación de pesos, dólares e instrumentos de deuda, y que el monto de estos últimos será superior al de las reservas en el Banco Central. Como se verá más adelante se plantearán dos opciones de política monetaria. En una de ellas las tasas de interés no variarán. Por lo tanto, el público comparará reservas con los recursos que 
provengan de la venta de sus títulos de deuda al Banco Central, mediante operaciones de mercado abierto. También podrán vender dólares o tomar créditos en dólares para comprar instrumentos de deuda en pesos. Por su parte, en el caso en que las tasas de interés sean flexibles y haya compra de dólares por el público, éstos estarían siendo adquiridos contra la salida de pesos de circulación.

$$
\left(M_{t+1}-M_{t}\right)+\left(e_{t}+1 D_{t+1}-e_{t} D_{t}\right)+\left(B_{t+1}+B_{t}\right)=0
$$

La solución del modelo se obtiene al equilibrar simultáneamente el mercado de pesos y el de dólares, dependiendo la clasificación de variables entre exógenas y endógenas, del régimen cambiario que se tome.

$$
\begin{aligned}
& D^{s}{ }_{t}=D^{d} t \\
& M^{s} t=M^{d} t
\end{aligned}
$$

El mercado de títulos gubernamentales está definido implícitamente por ecuación (5), y su condición de equilibrio se deriva directamente del cumplimiento de la expresión (6) y dicha restricción presupuestal (5).

\subsection{SOLUCIÓN DEL MODELO BAJO UN RÉGIMEN DE FLOTACIÓN LIBRE}

Como punto de referencia es conveniente determinar el comportamiento del tipo de cambio en un régimen de libre flotación ante distintas reglas de operación de la autoridad monetaria.

Como ya se adelantó, en este documento se consideran dos casos extremos. En el primero la política monetaria se orienta hacia el propósito de estabilizar las tasas de interés. Ello se refleja en la condición de equilibrio para el mercado de pesos (7).

$$
M^{s}{ }_{t}=M^{s}=1_{0}-11 \mathrm{r}
$$

Esta misma regla monetaria puede expresarse haciendo referencia a una situación en que las autoridades monetarias tienen como objetivo acomodar la demanda de base a una cierta tasa de interés, 
de tal suerte que $M^{s}$ se mantiene constante mientras el efecto de los cambios en las condiciones de mercado repercutirá principalmente en sus componentes: crédito y reservas. Esta situación corresponde al contexto del hecho estilizado (a) de la sección anterior.

Además, puesto que se está un régimen de flotación el Banco Central no interviene en absoluto en el mercado de cambios de tal forma que la oferta de dólares permanece constante por un monto D. En consecuencia, la condición de equilibrio para el tipo de cambio está dada por la expresión (8) suponiendo, sin pérdida de generalidad, que $d_{3} r_{t}=0$.

$$
\begin{aligned}
& e_{t}=\beta_{0}+\beta_{1} E_{t}\left[e_{t+1}-e_{t}\right]+\beta_{2} \varepsilon_{t} \\
& \beta_{0}=1 / d_{1}\left(d_{0}-D-d_{2} r\right) \\
& \beta_{1}=d_{2} / d_{1} \\
& \beta_{2}=1 / d_{1}
\end{aligned}
$$

A fin de encontrar la solución de expectativas racionales, se prueba como una posibilidad (9).

$$
e_{t+1}=e+\rho \varepsilon_{t+1}
$$

de donde se desprendería que

$$
E_{t}\left[e_{t+1}-e_{t}\right]=\rho E_{t}\left[\varepsilon_{t+1}-\varepsilon_{t}\right]=\rho E_{t}\left[u_{t+1}\right]=0
$$

lo cual significa que la trayectoria (9) satisface la ecuación (8) con $e=\beta_{0}$ y $\rho=\beta_{2}$. Como consecuencia de lo anterior se tiene que el tipo de cambio seguiría una caminata al azar sin tendencia según se expresa en la ecuación (11).

$$
\begin{aligned}
& e_{t+1}=e_{t}+\beta_{2}\left(\varepsilon_{t+1}-\varepsilon_{t}\right) \\
& e_{t+1}=e_{t}+\eta_{t+1} \\
& \eta_{t}=\beta_{2} u_{t+1}-N(0, \psi), \forall t \\
& \psi=\beta_{2} 2 \sigma^{2}
\end{aligned}
$$

El otro caso extremo para la regla monetaria sería aquél en el que se observara una plena flexibilidad de las tasas de interés, esencialmente como resultado del propósito del Banco Central de estabilizar el tipo 
de cambio utilizando toda la información de que dispone. Así, el comportamiento de las tasas de interés y de la oferta monetaria estarían dados por las ecuaciones (12) y (13).

$$
\begin{aligned}
& M^{s}{ }_{t}=1_{0}+1_{1}\left[\beta_{2} / \beta_{1} \varepsilon_{t}\right] \\
& r_{t}=e t-1 / \beta_{1} \varepsilon_{t}
\end{aligned}
$$

En términos del tipo de cambio, esto implica que la solución de expectativas racionales pasaría de ser la forma (11) la ecuación (14).

$$
\begin{aligned}
& e_{t+1}=\beta_{3}+\eta_{t}+1 \\
& \beta_{3}=1 / d_{1}\left(d_{0}-D\right)
\end{aligned}
$$

lo cual corresponde a un proceso estocástico estacionario con media $1 / d_{1}\left(d_{0}-D\right)$ y varianza $\psi$. Puede notarse además que bajo la regla monetaria (12) se cumple que $d_{2} E_{t}\left[e_{t+1}-e_{t}\right]=d_{3} r_{t}$. En el caso particular donde $d_{2}=d_{3}$ quiere decir que las tasas de interés se ajustan para impedir el arbitraje de rendimientos entre instrumentos denominados en pesos y dólares.

\subsection{RÉGIMEN DE BANDAS CREÍBLES}

El siguiente paso que se toma para integrar un marco de referencia para el análisis de la relación que existe entre la política monetaria y la sostenibilidad del régimen cambiario, consistió en tomar las ecuaciones (11) y (14) como punto de partida para modelar las expectativas del público sobre el tipo de cambio cuando éste flota dentro de una banda. Aunque el propósito de las secciones siguientes será el observar la mediad en que la selección de la política monetaria afecta la credibilidad de la banda, hasta el momento se supone que el nivel de reservas no tiene efecto alguno. Es decir, que los límites de intervención son perfectamente creíbles.

Se definen como parámetros de la banda de flotación al techo, $\tau, \mathrm{y}$ ancho, $\alpha$. En este caso se convendrá en que el Banco Central interviene en el techo para evitar una devaluación de la moneda local y en el piso para evitar una apreciación excesiva. 
Tenemos primero el caso en que las autoridades monetarias procuran tasas de interés estables. Las expectativas del público acerca del comportamiento del tipo de cambio estarían dadas básicamente por la ecuación (11), corregida por el efecto que tienen las bandas en la dinámica del tipo de cambio. Por notación es conveniente definir la función de densidad y la función de distribución de $\eta \operatorname{como} \mathrm{g}($.) y G(.) respectivamente. De esta manera se tienen que:

$$
E_{t} e_{t+1}=e_{t}+\int_{t-e_{t}-\alpha}^{t-e_{t}} \frac{\eta g(\eta)}{G\left(\tau-e_{t}\right)-G\left(\tau-e_{t}-\alpha\right)} d \eta
$$

La gráfica 6 corresponde a la ecuación (15), tomando los valores de $\tau=3, \alpha=6, \psi=1$. Destacan las ampliamente conocidas condiciones de "toque suave" características de los regímenes de bandas creíbles.

\section{Gráfica 6}

Tipo de Cambio Esperado VS Tipo de Cambio Observado

Tasas de interés no flexibles

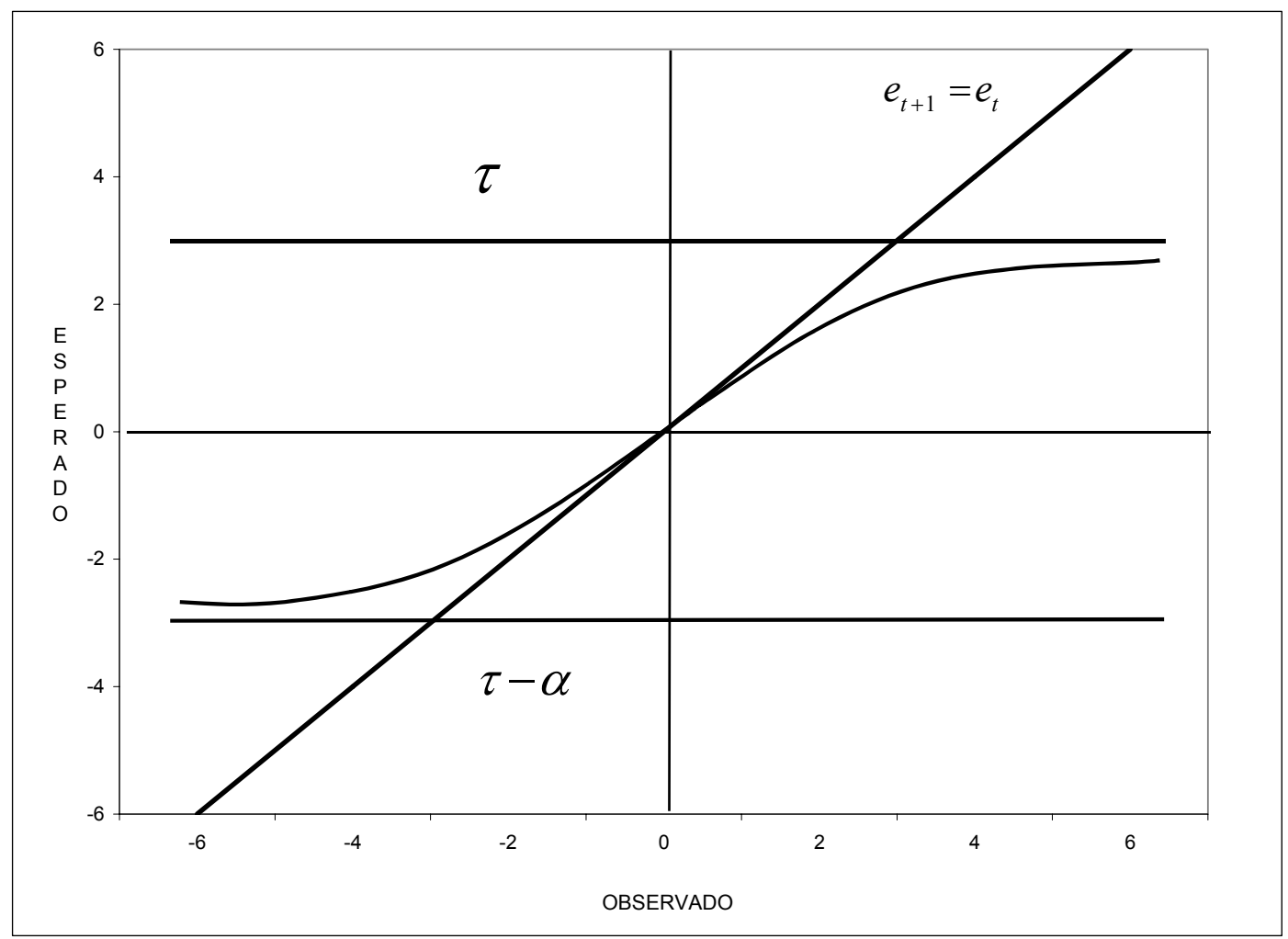


Por su parte, para el caso de flexibilidad de tasas de interés, a partir de la ecuación (14) se deriva el valor esperado del tipo de cambio el cual se muestra en la ecuación (16) y la gráfica 7. Ambas reflejan el hecho de que el tipo de cambio estaría seriamente no correlacionado en este contexto. Los valores utilizados para $\tau, \alpha$ son tales que la banda está centrada alrededor de un nivel de tipo de cambio igual a $\beta_{3}$. Nuevamente, sin pérdida de generalidad se supone que éste es igual a cero.

$$
E_{t} e_{t+1}=\beta_{3}+\int_{\tau-e_{t}-\alpha}^{\tau-e_{t}} \frac{\eta g(\eta)}{G\left(\tau-e_{t}\right)-G\left(\tau-e_{t}-\alpha\right)} d \eta
$$

\section{Gráfica 7}

Tipo de Cambio Esperado Vs. Tipo de Cambio Observado

Tasas de interés flexibles

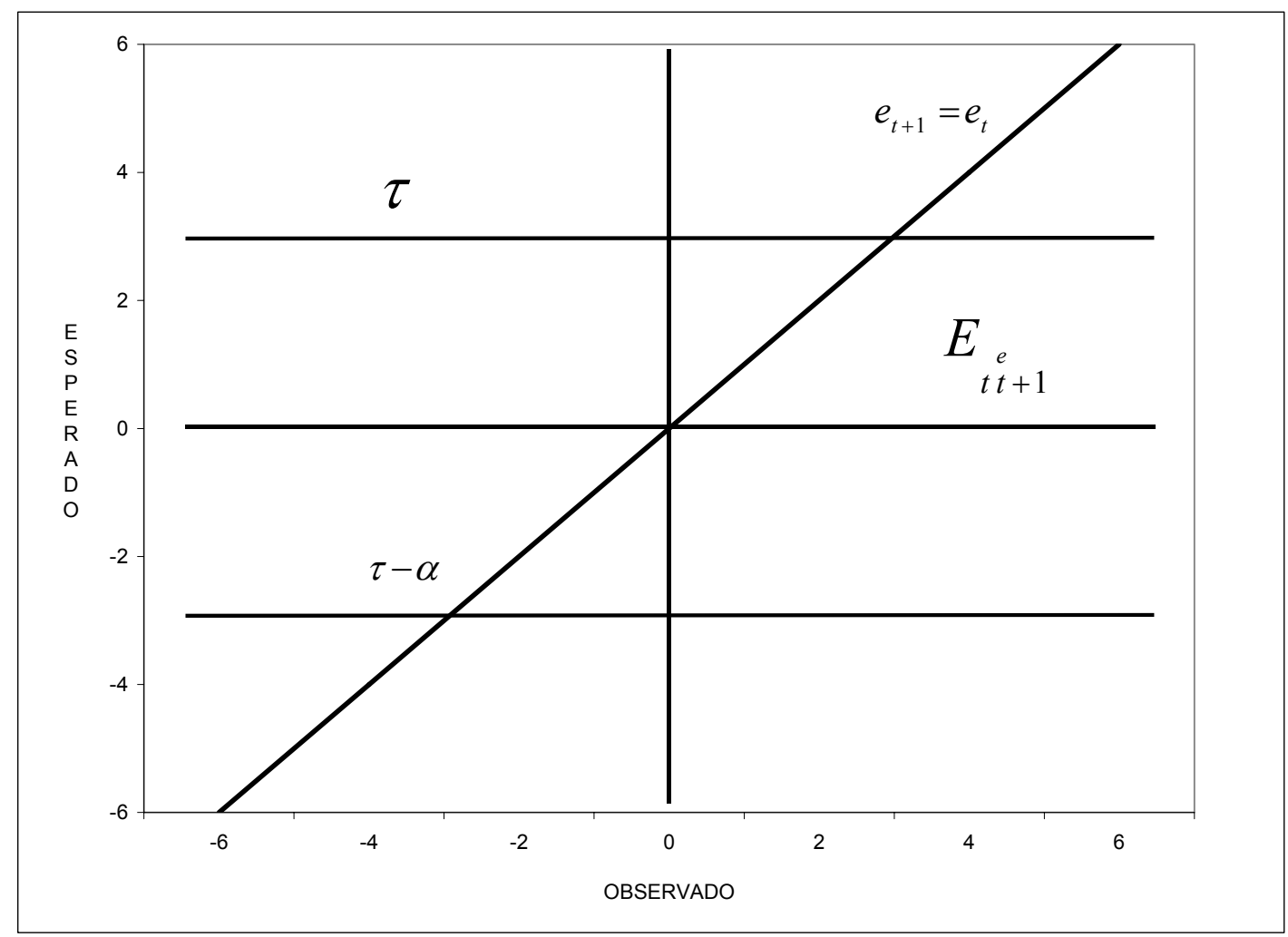

En ambos ejemplos, dado el supuesto que se hace de que el régimen cambiario es totalmente creíble, las intervenciones del Banco Central en el mercado de cambios serían poco frecuentes y su monto 
reducido. Para ilustrar este aspecto vale la pena recordar que cualquier choque de demanda de dólares que llevase el tipo de cambio de libre flotación por encima del techo de la banda, tendría que ser compensado por una pérdida de reservas internacionales del Instituto Emisor. Lo contrario ocurriría si hubiera presiones para llevar al tipo de cambio por debajo del piso de intervención. Así pues, tomando las ecuaciones (2) y (11) se tendría que el valor esperado de la intervención en el caso de tasas de interés no flexibles estaría dado por la ecuación (17), cuyas características se ven con más facilidad con la ayuda de la gráfica 8 .

$$
\begin{aligned}
& E_{t}\left(R_{t+1}-R_{t}\right)=\int_{-\infty}^{\tau-\alpha-e_{t}} d_{1} \eta g(\eta) d \eta+\int_{\tau-e_{t}}^{\infty} d_{1} \eta g\left(\eta_{t}\right) d \eta_{t} \\
& =\mathrm{d}_{1} / 2 \sqrt{\pi\left(\frac{1}{\operatorname{Exp}\left(\tau-e_{t}\right)^{2}}-\frac{1}{\operatorname{Exp}\left(\tau-\alpha-\mathrm{e}_{\mathrm{t}}\right)^{2}}\right)}
\end{aligned}
$$

\section{Gráfica 8}

Valor Esperado de las Intervenciones en el Mercado de Cambios

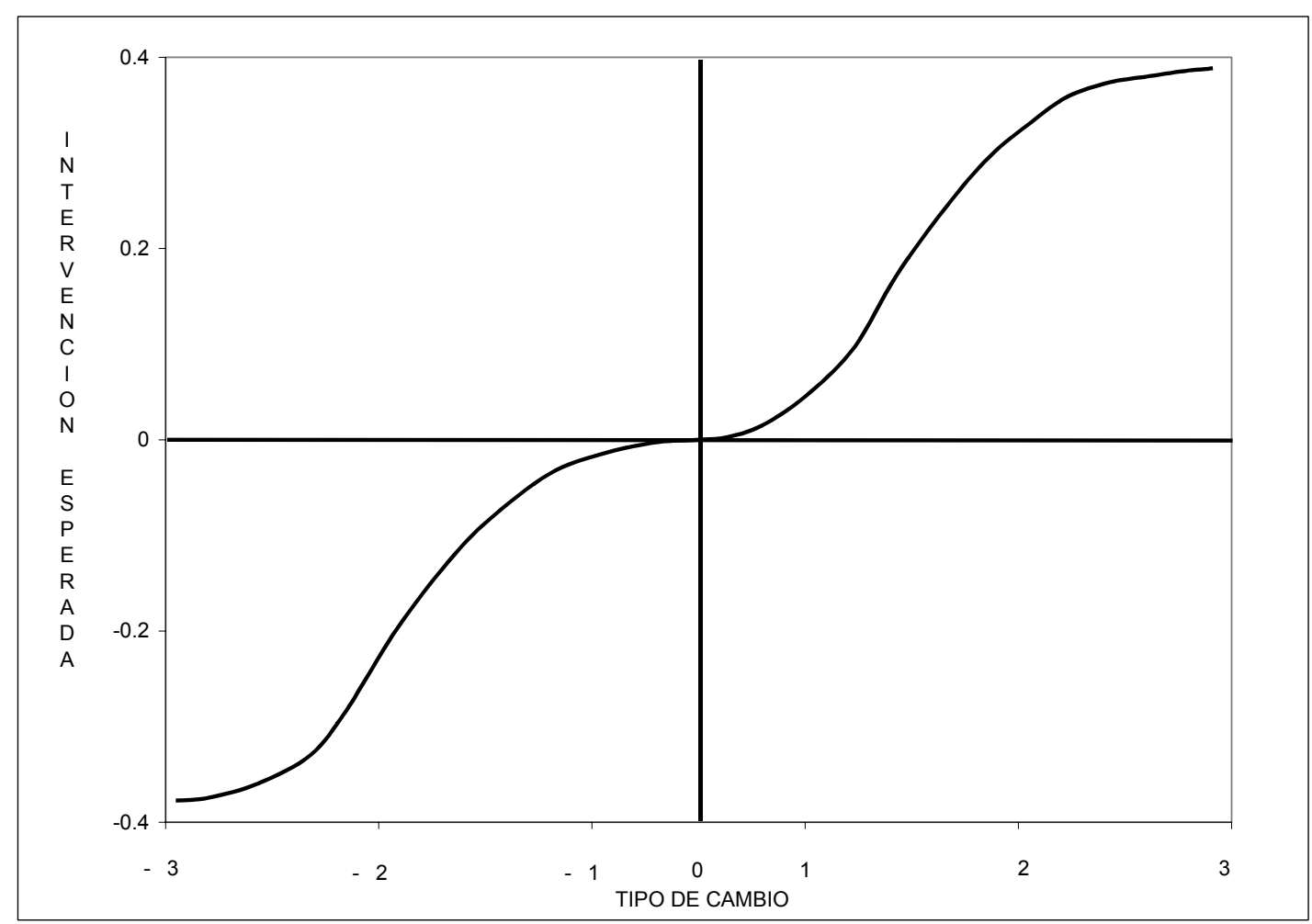


Llama la atención de este ejemplo que al acercarse el tipo de cambio a los límites de intervención, el ritmo al cual crece la intervención promedio se reduce, precisamente por el efecto que la credibilidad de la bandas tiene sobre el comportamiento del tipo de cambio.

Por su parte, la ecuación (18) es el valor esperado de la intervención en el caso de tasas de interés flexibles. Aquí resalta el hecho de que, para un nivel dado de D, aquél es una cantidad fija independiente delnivel del tipo de cambio, según aparece en la gráfica 9 usando los mismos parámetros de la gráfica 7.

$$
\begin{aligned}
E_{t}\left(R_{5^{* 1}}-R_{t}\right) & =\int_{-\infty}^{\infty} d_{1} \eta g\left(\eta_{t}\right) d \eta_{t}+\int_{\tau-\beta t 3}^{\infty} d_{1} \eta g\left(\eta_{t}\right) d \eta_{t} \\
& =\mathrm{d}_{1} / 2 \sqrt{\pi}\left(\frac{1}{\operatorname{Exp}\left(\tau-\beta_{3}\right)^{2}}-\frac{1}{\operatorname{Exp}(\tau-\alpha-\beta 3)^{2}}\right)
\end{aligned}
$$

\section{Gráfica 9}

Valor Esperado de las Intervenciones en el Mercado de Cambio

Tasas de interés flexibles

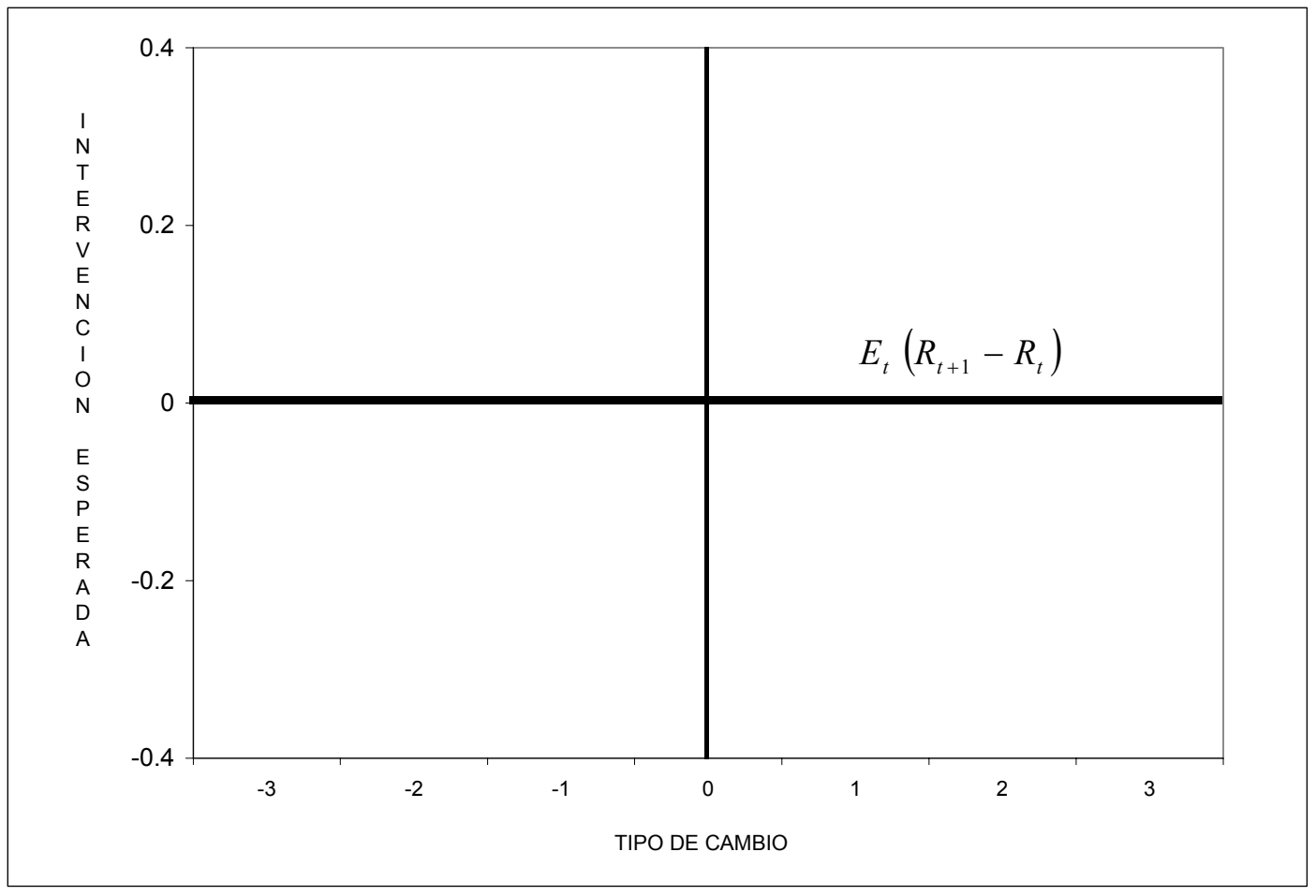


Este resultado nos permite adelantar un criterio de sostenibilidad del régimen cambiario y que corresponde al diseño de una banda tal que $\mathrm{E}_{t}\left(\mathrm{R}_{\mathrm{t}+1}-\mathrm{R}_{\mathrm{t}}\right)=0$. Así igualando la ecuación (18) a cero y resolviendo se obtiene,

$$
(2 \tau-\alpha) / 2=\beta_{3}
$$

Sin que sea sorprendente, la expresión (19) corresponde a una banda centrada alrededor de $\beta_{3}$. Si esta última es igual a cero, se obtiene la expresión para $\tau$ y $\alpha$

$$
\tau=\alpha / 2
$$

\subsection{RÉGIMEN DE BANDA CON CREDIBILIDAD ENDÓGENA.}

La sostenibilidad de la política cambiaria depende de que el Banco Central cuente, hoy y en el futuro, con reservas suficientes para hacer frente a la demanda de dólares en el mercado, a un tipo de cambio que se encuentre dentro de los límites de flotación.

Esto implica que, en cada período, los participantes en el mercado evalúan la credibilidad de las bandas tomando en cuenta esencialmente tres factores: por un lado, la posición del tipo de cambio en relación con el piso o techo de la banda, en segundo lugar, la volatilidad de los choques sobre la demanda de dólares y, en tercer lugar, el nivel de reservas disponibles.

Una opción consiste en pensar que los agente4s económicos cada período hacen este cálculo estimando la probabilidad de que la economía enfrente, en el siguiente período un choque exógeno de tal magnitud que rebase la capacidad de las reservas internacionales para sostener el techo de la banda en su nivel predeterminado. 
En el caso del piso de la banda la situación es diferente debido a que, en principio, no existe una razón por la que la acumulación de reservas deba tener un límite, sobre todo mientras las autoridades puedan esterilizar sin mayores problemas el impacto monetario de las entradas de capitales ${ }^{2}$.

Si bien el modelo puede generalizarse sin grandes dificultades para considerar tanto la posibilidad de que el tipo de cambio se devalúe o revalúe más allá de los límites de intervención, los ejercicios que siguen se concentrarán sólo en la primera de las posibilidades.

Con base en estas ideas, en el escenario de tasas de interés menos flexibles la credibilidad que el público conceda al techo de la banda estaría dada por la ecuación (21). Esta por su parte es la probabilidad de que el tipo de cambio observado se devalúe por encima del nivel del techo de la banda dado que el tipo de cambio sombra se ubicara por arriba de dicho techo, y un ejemplo con los mismos parámetros usados la sección anterior por la gráfica 10.

$$
\delta_{t}=\left(1-G\left(d_{1} R_{t}+\tau-e_{t}\right)\right) /\left(1-G\left(\tau-e_{t}\right)\right)
$$

Gráfica 10

Probabilidad que el Techo de la Banda Deje de Ser una Restricción Efectiva Tasas de interés no flexibles

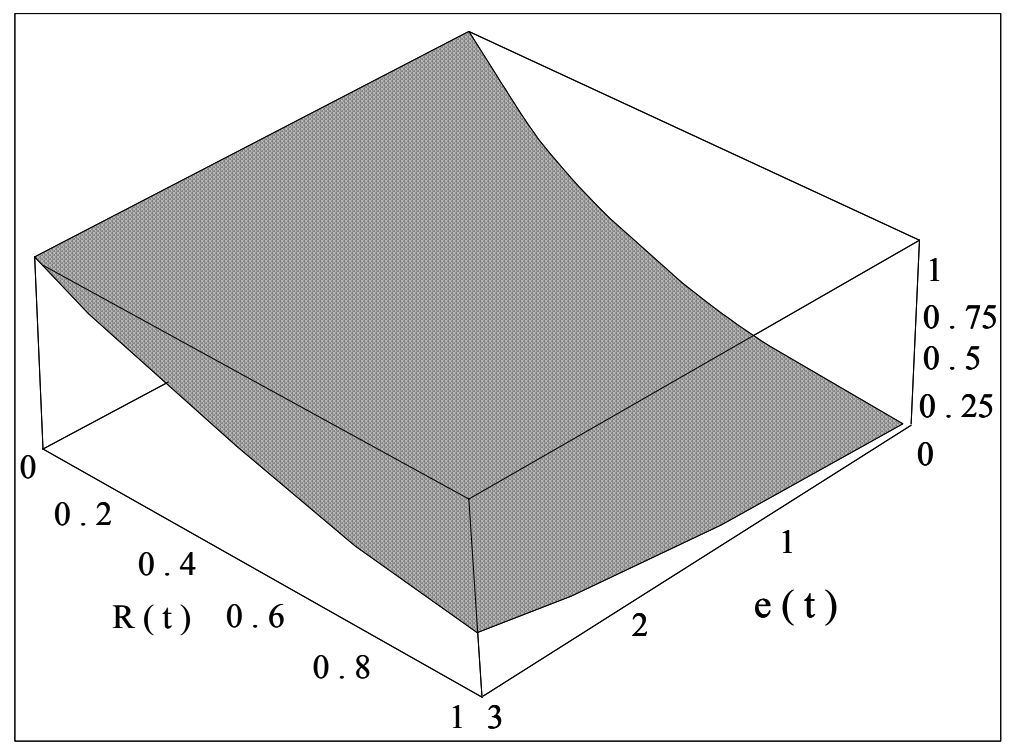

2 Esto no es estrictamente cierto en la práctica puesto que la esterilización implica para el instituto emisor la colocación de instrumentos de deuda en pesos a una tasa mayor que aquélla a la que invierte la reserva internacional. En consecuencia una esterilización cuantiosa podría generar un déficit cuasi-fiscal significativo. 
El hecho de que la credibilidad del régimen cambiario dependa ahora de la historia de pasadas intervenciones afecta de manera apreciable la dinámica misma del tipo de cambio. Específicamente, la ecuación (15) se modifica quedando como sigue:

$$
E_{t} e_{t+1}=e_{t}+(1-\delta) \int_{\tau-\alpha-e_{t}}^{\tau-e_{t}} \frac{\eta g(\eta)}{G\left(\tau t-e_{t}\right)-G\left(\tau-e_{t}-\alpha\right)} d \eta+\delta \frac{\eta g(\eta)}{1-g\left(\tau-e_{t}-\alpha\right.} d \eta
$$

Este resultado puede presentarse modificando la gráfica 8 con la inclusión de la reservas internacionales como una dimensión adicional. Destaca cómo cambia la propiedad de "toque suave" a medida que el nivel de reservas internacionales disminuye. De hecho, cuando las reservas son muy bajas la percepción del público sobre la sostenibilidad de la banda es mínima y, en consecuencia, el tipo de cambio esperado es similar al que existiría bajo el régimen de libre flotación con tasas de interés poco flexibles.

\section{Gráfica 11-a}

Tipo de Cambio Esperado VS Tipo de Cambio Observado

Tasas de interés no flexibles

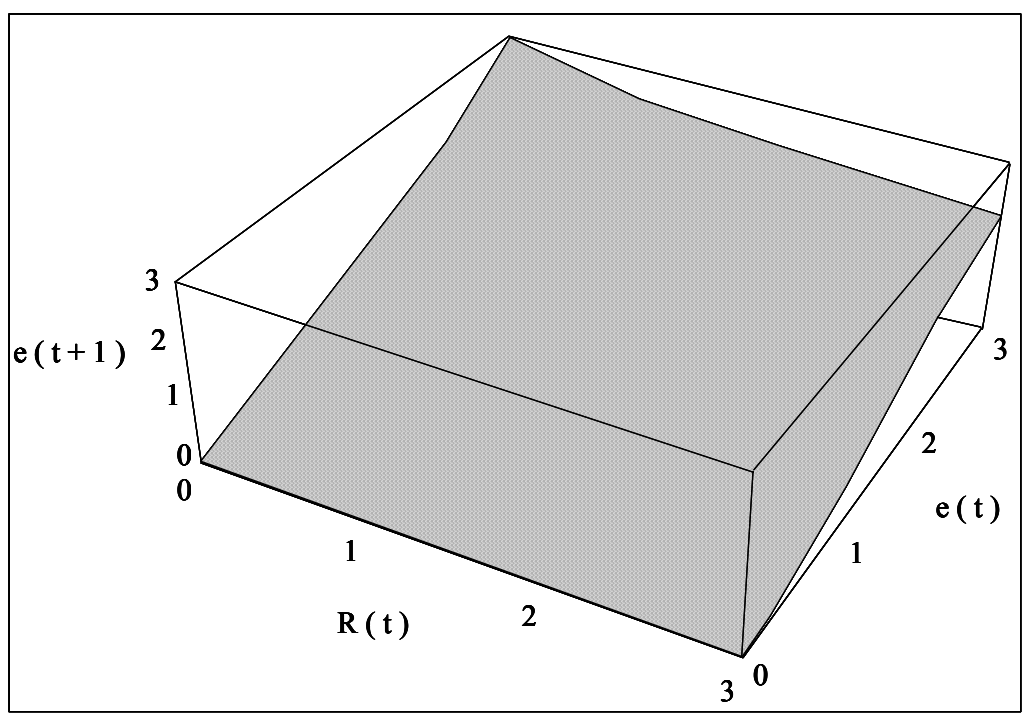


Gráfica 11-b

Tipo de Cambio Esperado VS Tipo de Cambio Observado

Tasas de interés no flexibles

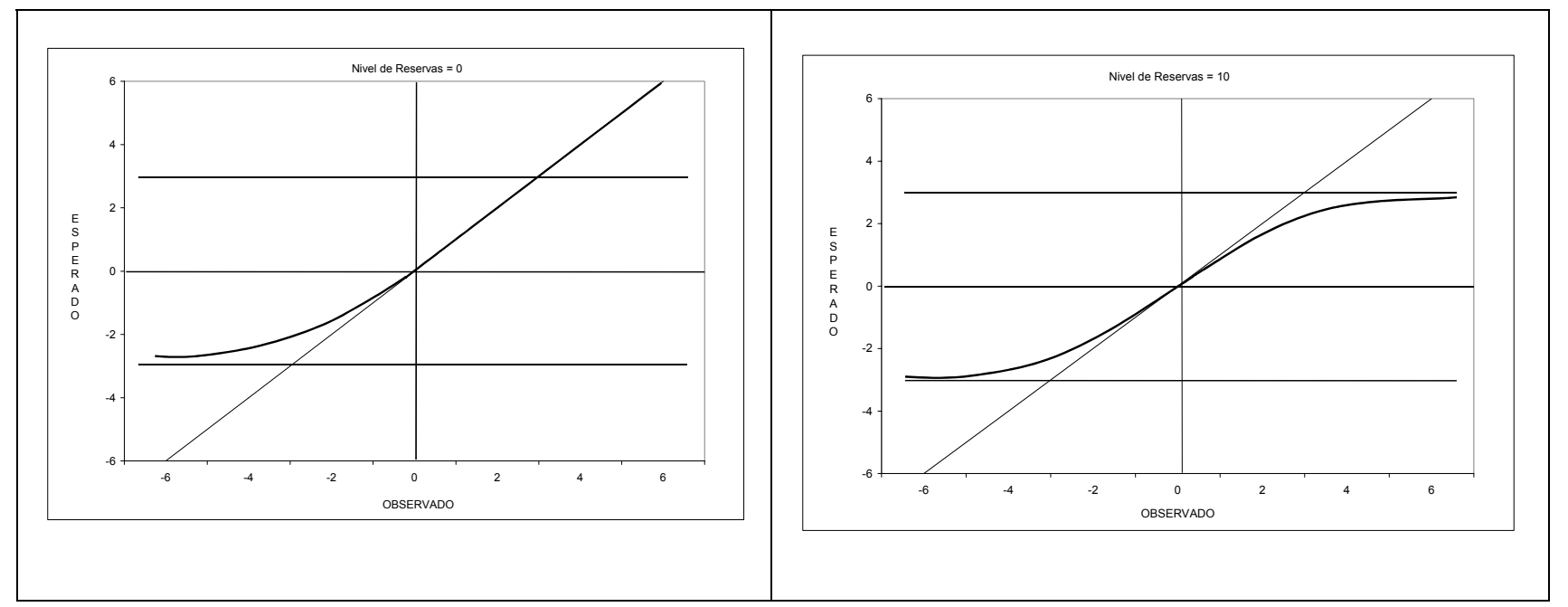

Por otro lado, cuando las tasas de interés son flexibles la probabilidad de que la banda deje de ser una restricción relevante se define por la ecuación (23), y la relación entre el tipo de cambio observado y esperado por la (24). Para estas ecuaciones aparecen sus correspondientes ejemplos en las gráficas 12 y 13 , usando los mismos parámetros de la gráfica 9.

$$
\begin{aligned}
& \delta_{t}=\left(1-G\left(d_{1} R_{t}+\tau-\beta_{3}\right)\right) /\left(1-G\left(\tau-\beta_{3}\right)\right) \\
& E_{t} e_{t+1}=\beta_{3}+(1-\delta) \int_{-\alpha-\beta_{3}}^{\tau-\beta_{3}} \frac{\eta g(\eta)}{G\left(\tau-\beta_{3}\right)-G\left(\tau-\beta_{3}-\alpha\right)} d \eta+\delta \int_{\tau-\beta_{3}}^{\alpha} \frac{\eta g(\eta)}{1-G\left(\tau-\beta_{3}-\alpha\right)} d \eta
\end{aligned}
$$




\section{Gráfica 12}

Probabilidad que el Techo de la Banda deje de ser una Restricción Efectiva Tasa de interés flexibles

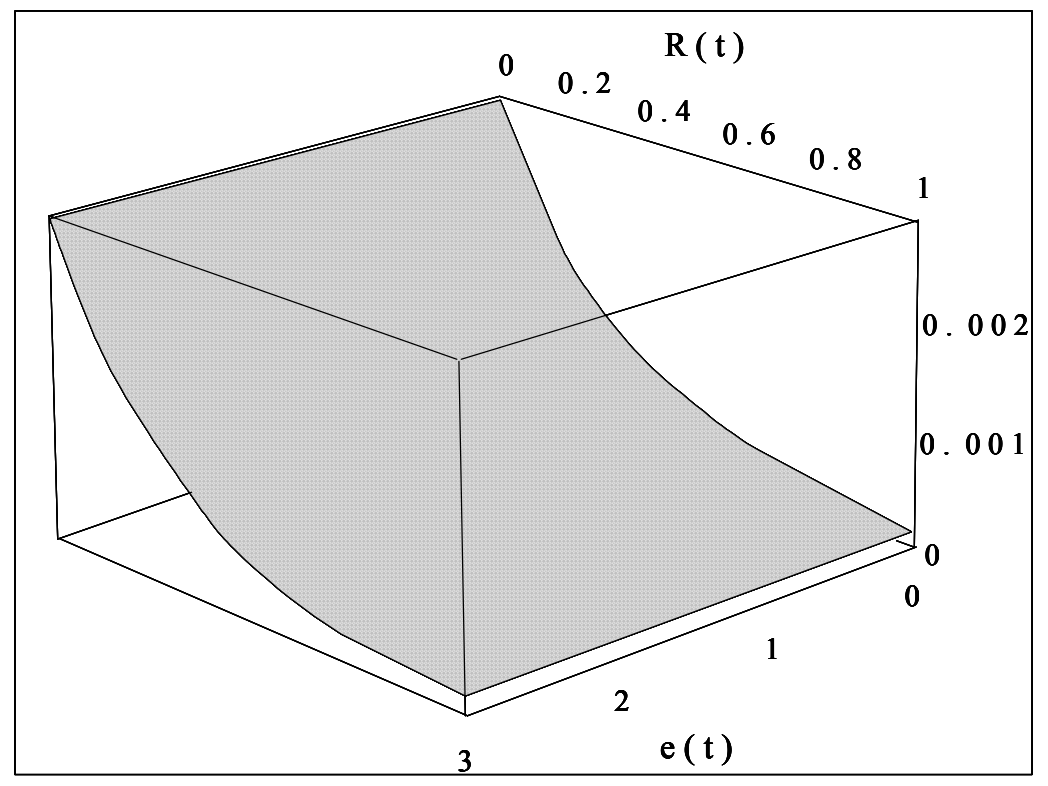

En este escenario la probabilidad de que deje de operar eficazmente el techo de la banda también aumenta al perderse las reservas internacionales, sin embargo ésta se mantiene en niveles muy bajos prácticamente para cualquier combinación de tipo de cambio y reservas. Esto se observa con más claridad en la gráfica 13 donde el tipo de cambio esperado no varía con las intervenciones del Banco Central en el mercado de cambios a no ser que las reservas desciendan considerablemente. 


\section{Gráfica 13}

Tipo de Cambio Esperado VS Tipo de Cambio Observado

Tasa de interés flexibles

(los valores de $e_{t+1}$ están multiplicados por 10)

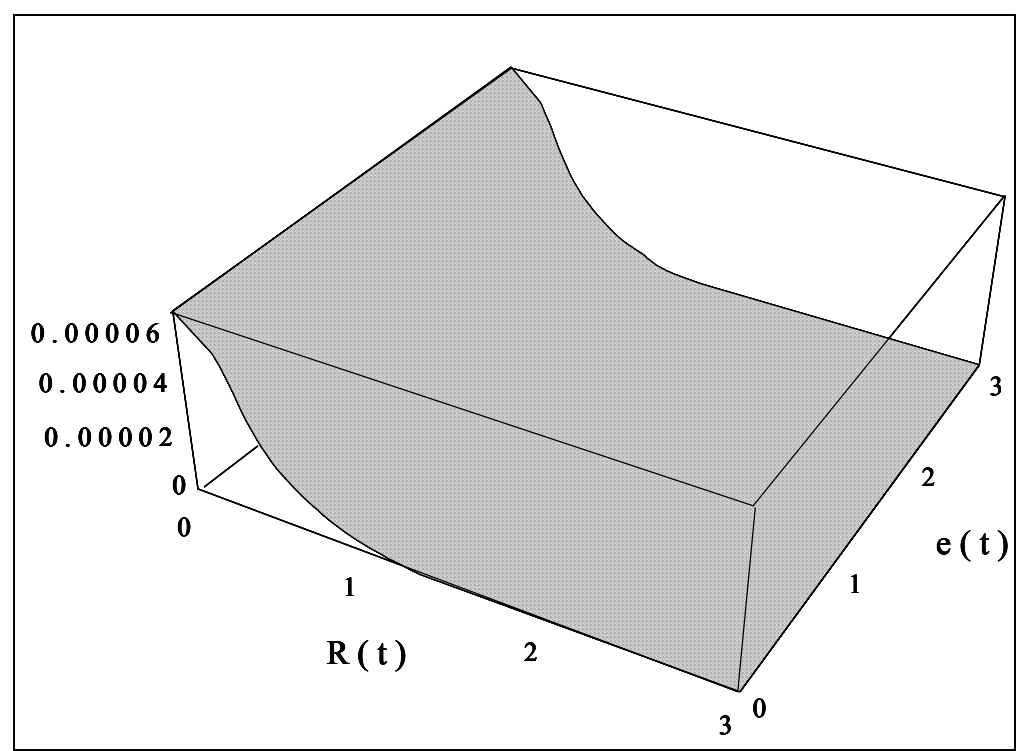

\subsection{SOSTENIBILIDAD DEL RÉGIMEN CAMBIARIO}

Tomando como base las ecuaciones de expectativas del tipo de cambio (22) y (24), el objetivo de esta sección consiste en avanzar hacia una definición operativa de sostenibilidad del régimen cambiario, y de ahí a establecer algunos criterios para la selección de una combinación deseable de política monetaria y cambiaria.

Con el propósito de mostrar con más detalle el método utilizado el ejercicio se presenta en tres etapas. En la primera se simula el comportamiento de la paridad, expectativas de devaluación y nivel de reservas para el caso de un régimen de bandas fijas, tomando las dos opciones de política monetaria a que se ha hecho referencia lo largo del documento. En la segunda se propone una definición más general del régimen cambiario expresando, en términos de dos parámetros, un continuo de esquemas que van desde el tipo de cambio fijo hasta la libre flotación. Finalmente, en la tercera se elaboran ejemplos que permiten tener una idea de la forma en que la sostenibilidad de la política de tipo de cambio depende de definiciones alternativas de la regla monetaria y del propio diseño del régimen cambiario. 


\subsection{SOSTENIBILIDAD DE UN ESQUEMA DE BANDAS FIJAS}

La secuencia que se sigue en las simulaciones arriba mencionadas se inicia con una economía que cuenta con cierto monto de reservas y en la que el tipo de cambio está en el centro de la banda. En cada momento los participantes en el mercado formulan sus expectativas de conformidad con las ecuaciones (22) y (24) lo cual, sustituido en la ecuación (7) nos lleva a un nivel de tipo de cambio que se referirá como "sombra" para efectos de notación. Si dicho valor se encuentra fuera de los límites de la banda, el Banco Central interviene comprando o vendiendo dólares para sostener el compromiso cambiario. Si las reservas son suficientes, el ejercicio se hace una vez más. Si no, se detiene.

Este ciclo que va desde el nivel de reservas inicial hasta el colapso cambiario se repite varias veces y se registran algunos datos como son: el promedio simple de los periodos de vigencia del esquema, el tiempo que transcurre entre la primera intervención en el techo de la banda y el colapso cambiario, el número de ejercicios en los que el régimen cambiario resulta insostenible y el nivel del tipo de cambio al final del ejercicio. Estos elementos de información se utilizan como indicadores de la sostenibilidad de la política cambiaria.

La gráfica 14 presenta uno de estos ciclos correspondiente al caso de tasas de interés menos flexibles, llamando la atención la forma en que el modelo se aproxima a los hechos estilizados descritos en la sección 2. Durante los primero 55 períodos se observan fluctuaciones de la paridad características de una caminata al azar. Por su parte, la plena credibilidad de la banda queda de manifiesto toda vez que el rango alrededor del que fluctúa el tipo de cambio esperado se mantiene entre -0.2 y 0.2. En el lapso que va desde $\mathrm{t}=25$ hasta 35 se suceden varios eventos desfavorables que si bien se tradujeron en pérdida de reservas, no empezaron a afectar la credibilidad de la banda sino hasta muy cerca del período 35. Para ver esto hay que notar cómo, en ese momento, el tipo de cambio esperado repunta ligeramente aun cuando el tipo de cambio observado se mantiene constante en el nivel del techo de la banda.

A partir de entonces puede decirse que el régimen cambiario se vuelve muy vulnerable. Así pues, a pesar de que se presentan varios choques favorables no es posible reconstruir el nivel de reservas y, tanto el tipo de cambio sombra como el esperado se mantienen por encima de la paridad central. Más 
aún, el tipo de cambio observado se queda muy cerca del techo. Como es de esperarse, la combinación de bajos niveles de reservas y un tipo de cambio elevado hacen que sea muy probable observar un evento que desencadene una corrida. Esto ocurre en $\mathrm{t}=56$ cuando un acontecimiento exógeno, relativamente menor si se compara con lo sucedido 30 períodos antes, hace que las reservas caigan por debajo de un cierto nivel crítico. En ese instante el tipo de cambio esperado salta bruscamente hacia el techo de la banda. Si bien se restablece el equilibrio en el mercado de dólares, a estas alturas es virtualmente imposible que el régimen cambiario pueda sobrevivir en un contexto de tasas de interés poco flexibles, ya que para restablecer la credibilidad debe acumularse reservas y la probabilidad de que ello ocurra comparada con la de enfrentar un choque desfavorable es mínima.

Este ejemplo nos lleva directamente a un tema fundamental de política económica que tiene que ver con la diferencia que existe entre el momento en que se produce el colapso cambiario y aquél en el que las condiciones han cambiado de tal manera que el régimen de bandas es insostenible. Concretamente, mientras se cuente con reservas abundantes, el tipo de cambio responde a los conocidos efectos estabilizadores de las bandas creíbles. Por eso, durante ese lapso es posible operar sin mayor problemas una política monetaria que procure simultáneamente la estabilización de las tasas de interés y/o base monetaria y de la paridad, lo cual sin duda resulta atractivo para las autoridades. Sin embargo, una vez que se llega una cierta combinación "crítica" de tipo de cambio y reservas el proceso que determina el comportamiento del tipo de cambio deja de ser sostenible para convertirse en uno inestable. Desafortunadamente, la transición no es fácil de distinguir. Esto plantea un problema serio para las autoridades por que el deterioro en la credibilidad de la banda no implica que se presente de inmediato una corrida contra la moneda nacional, lo cual podría posponer la adopción de medidas correctivas. No obstante, bajo las nueva circunstancias y en promedio, sólo será cuestión de tiempo para que se presente el colapso cambiario. 
Gráfica 14

Ejercicio de Simulación del Comportamiento del Mercado de Cambios.

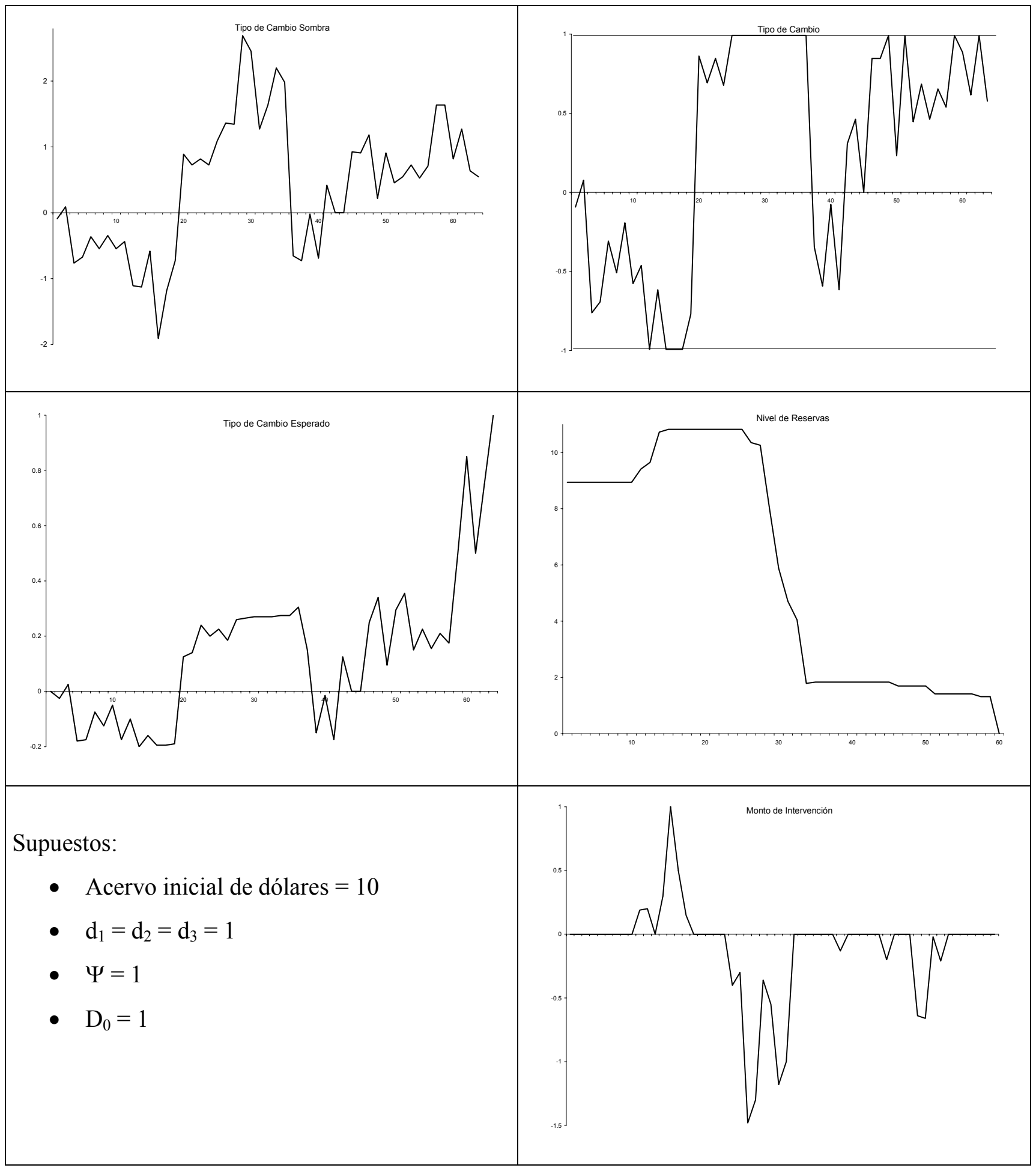


Esta idea puede expresarse también dibujando las curvas de nivel de la gráfica 10 con los parámetros del ejercicio de la gráfica 14. Ahí se observa que mientras el tipo de cambio y las reservas se encuentren en el área "A", la política de estabilización simultánea de las tasas de interés y el tipo de cambio son en esencia compatibles. Esta situación comienza a cambiar de manera fundamental una vez que se atraviesa la frontera "BB", a partir de la cual las expectativas de incumplimiento del compromiso cambiario aumentan con rapidez crecientes, lo cual ciertamente actúa en una dirección contraria al objetivo de estabilidad cambiaria.

\section{Gráfica 15}

Probabilidad que el Techo de la Banda Deje de Ser Una Restricción Efectiva

Tasas de interés no flexibles

(cada línea representa 10\% adicional de probabilidad)

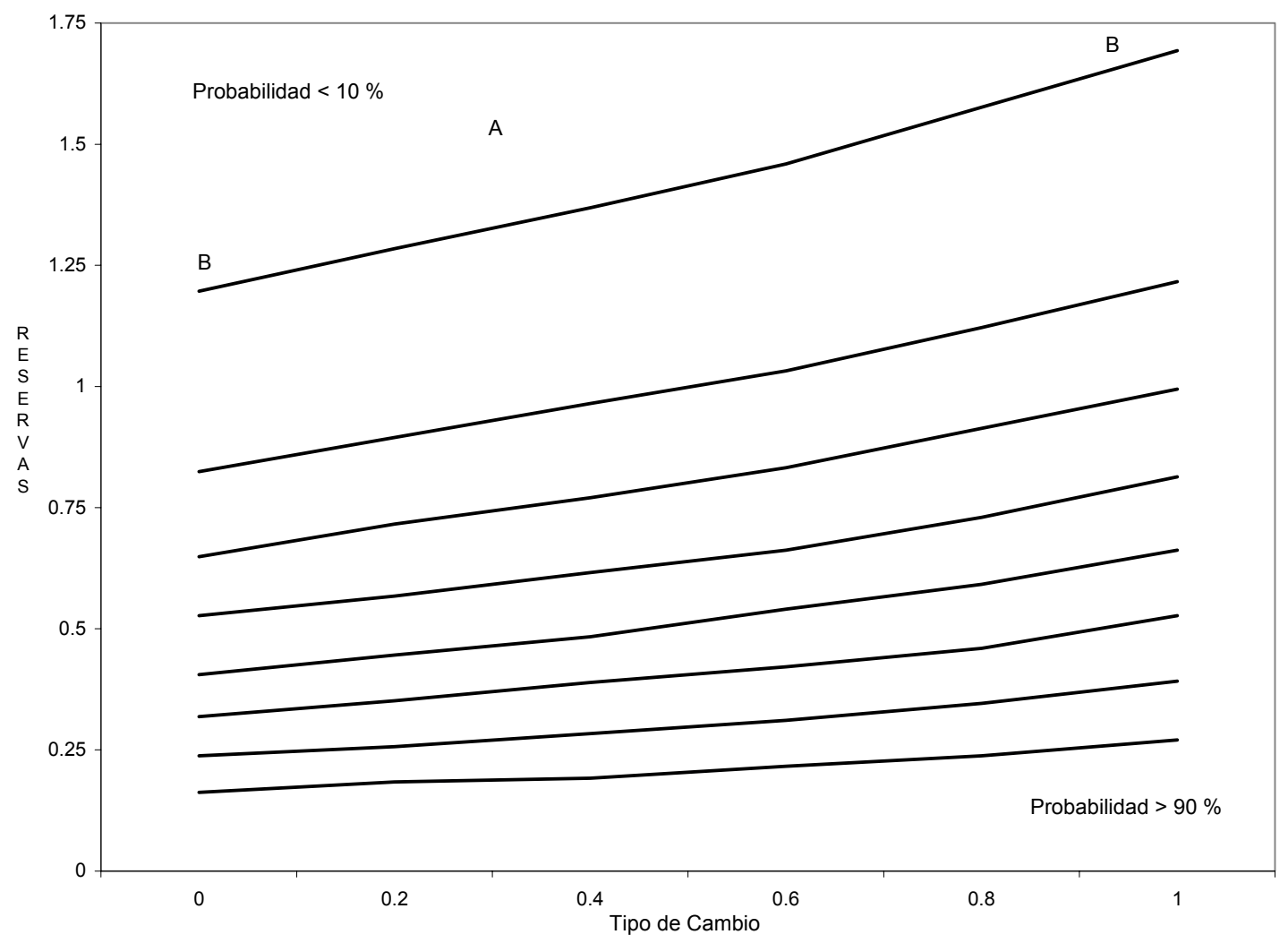

La gráfica 16-a da una idea de lo que sucede con el nivel esperado del tipo de cambio al variar las reservas. La forma de las curvas refleja como va perdiendo fuerza la condición de "toque suave" cuando se tienen pocas reservas. Destaca como para niveles de reservas por debajo de 2.0 el tipo de cambio esperado es apreciablemente mayor al que se tiene con bandas creíbles. En la medida en que 
esto sucede la posibilidad de que el tipo de cambio regrese hacia el centro de la banda se reduce con lo cual las intervenciones tenderán a ser más grandes y frecuentes como ya se dijo repetidamente. Por su parte, la gráfica 16-b ilustra el mismo concepto en términos de las diferencias entre el tipo de cambio esperado con bandas de credibilidad endógena versus lo que ocurre cuando las bandas son plenamente creíbles.

\section{Gráfica 16-a}

Tipo de Cambio Esperado

Tasas de interés no flexibles

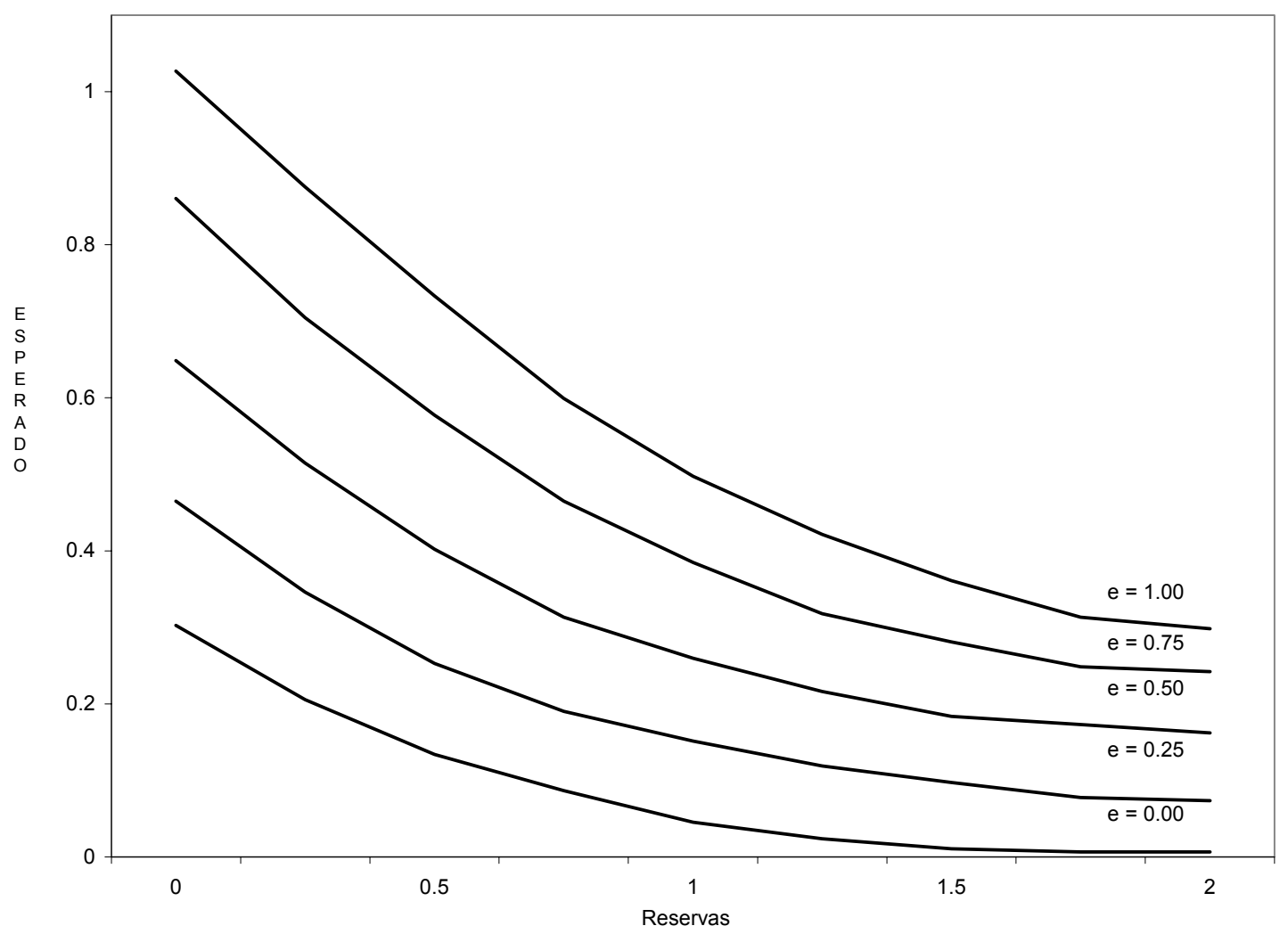


Gráfica 16-b

Tipo de Cambio Esperado con Bandas con Credibilidad Endógena Menos Tipo de Cambio Esperado con Bandas Creíbles

Tasas de interés no flexibles

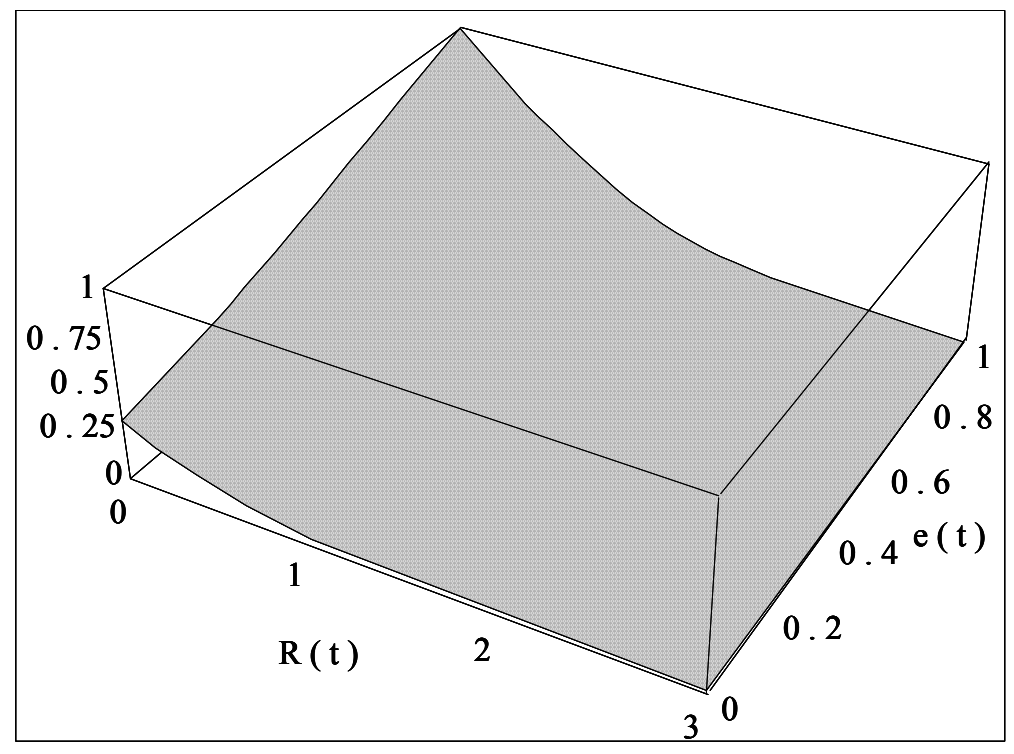

Esta situación contrasta con lo que sucede cuando las tasas de interés son plenamente flexibles. En la gráfica 17 se ve como para el mismo conjunto de parámetros de la gráfica 14 se obtiene una secuencia del tipo de cambio en la cual las fluctuaciones se mantienen cerca de la media y, aunque las intervenciones son frecuentes, éstas se presentan alternadamente en ambos límites de la banda. Así pues, bajo esta definición de la política monetaria parece ser considerablemente difícil alcanzar niveles tan pequeños de reservas, o un choque exógeno tan grande, tales que el tipo de cambio esperado salte al techo de la banda iniciando así un proceso irreversible de pérdida de reservas. 


\section{Gráfica 17}

Ejercicio de Simulación del Comportamiento del Mercado de Cambios

Tasas de interés flexibles

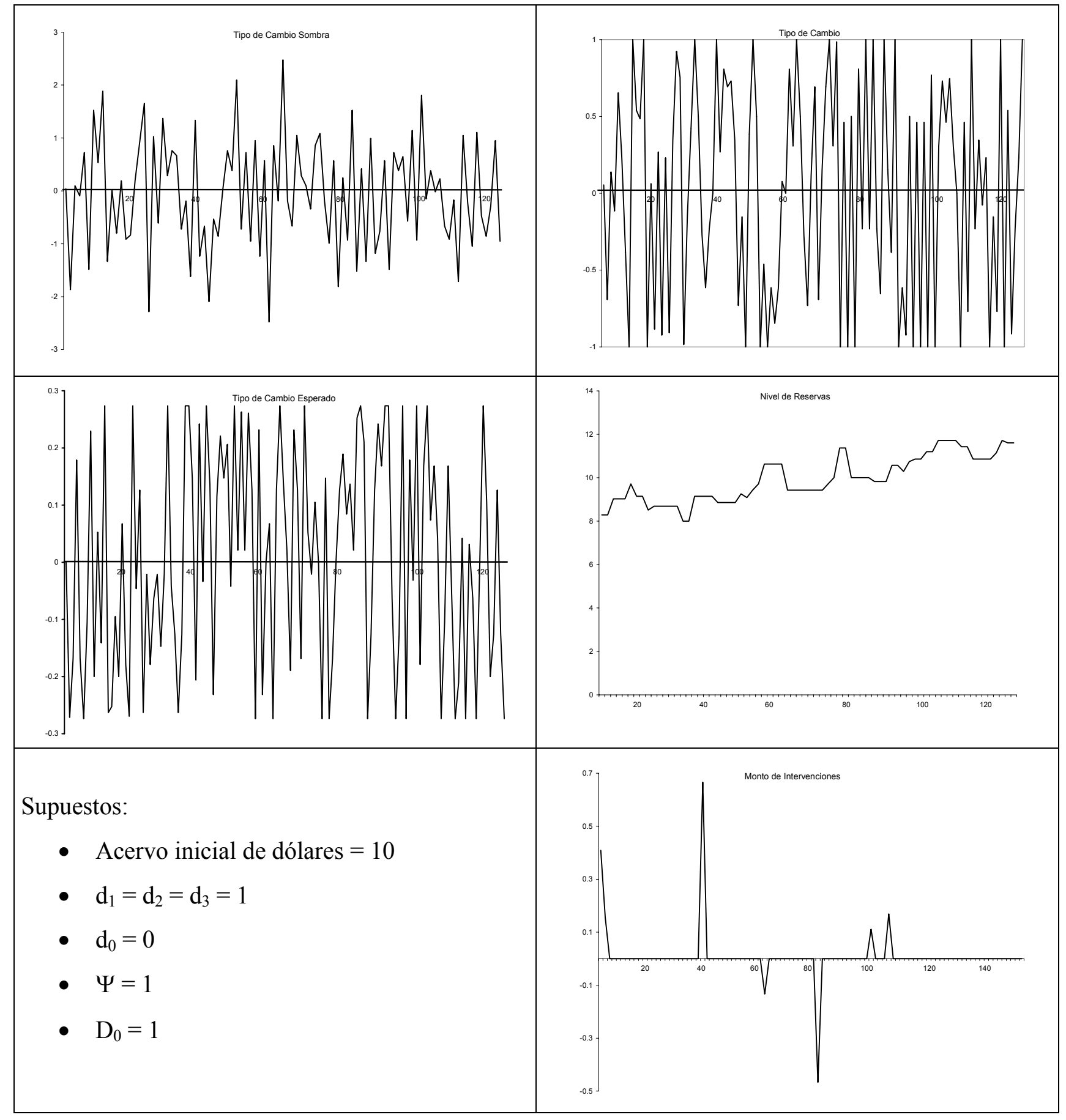




\subsubsection{MODELO DE BANDAS "VISCOSAS"}

Toda vez que los ejercicios de la sección anterior nos muestran que el modelo permite generar escenarios congruentes con los hechos estilizados listados en la sección 2, lo que seguiría es preguntarse bajo que combinaciones de parámetros y política monetaria sería posible evitar el colapso de las bandas cambiarias, y más aún, si esto es del todo posible en el escenario detasas de interés fijas.

Antes de intentar responder esta pregunta conviene hacer una observación adicional. Aunque es cierto que con un esquema de bandas fijas el propósito que pudieran tener las autoridades monetarias de estabilizar, simultáneamente y dentro de ciertos rangos, tipo de cambio y tasas de interés puede ser muy vulnerable a choques externos y a la dinámica de formación de expectativas, también debe aceptarse que hay muchas otras fórmulas posibles.

Una manera parsimoniosa de caracterizar esta amplia gama alternativas se tiene a través del concepto de "banda viscosa". En una banda de este tipo su paridad central se define como un promedio móvil de observaciones pasadas del tipo de cambio. Si éste incluye muchas observaciones, el centro de la banda fluctuará muy poco. En contraste, si la "memoria" de la banda es corta las variaciones serán más marcadas. Por su parte el ancho de la banda puede establecerse arbitrariamente, por ejemplo, en términos de la volatilidad de los choques exógenos de la demanda por dólares. Por lo tanto, una combinación de poca "memoria" y una banda amplia es aproximadamente equivalente a una flotación libre de la paridad, mientras una "memoria" larga pero una banda angosta es muy similar a un régimen de tipo de cambio fijo.

La gráfica 18 y 19 proporcionan un ejemplo de cómo operarían las bandas viscosas en simulaciones generadas por los mismo procesos de la sección anterior. Para el caso de tasas de interés menos flexibles, si bien las intervenciones se hacen menos frecuentes y de menor tamaño, a cambio se tiene un comportamiento más cercano al de una caminata al azar, misma que se tendría en el caso de una flotación libre bajo esta regla de política monetaria. Por su parte, se ve que un esquema viscoso no aporta ningún elemento adicional de estabilidad al régimen cambiario cuando la política de tasas es flexible, e incluso puede generar, si bien marginalmente, mayor volatilidad al tipo de cambio dentro de la banda como resultado de los efectos que tiene la realineación frecuente, si bien pequeña, de los límites de intervención (ver Werner, 1994). 
Gráfica 18

Ejercicio de Simulación del Comportamiento del Mercado de Cambios con Bandas Viscosas

Tasas de interés no flexibles.

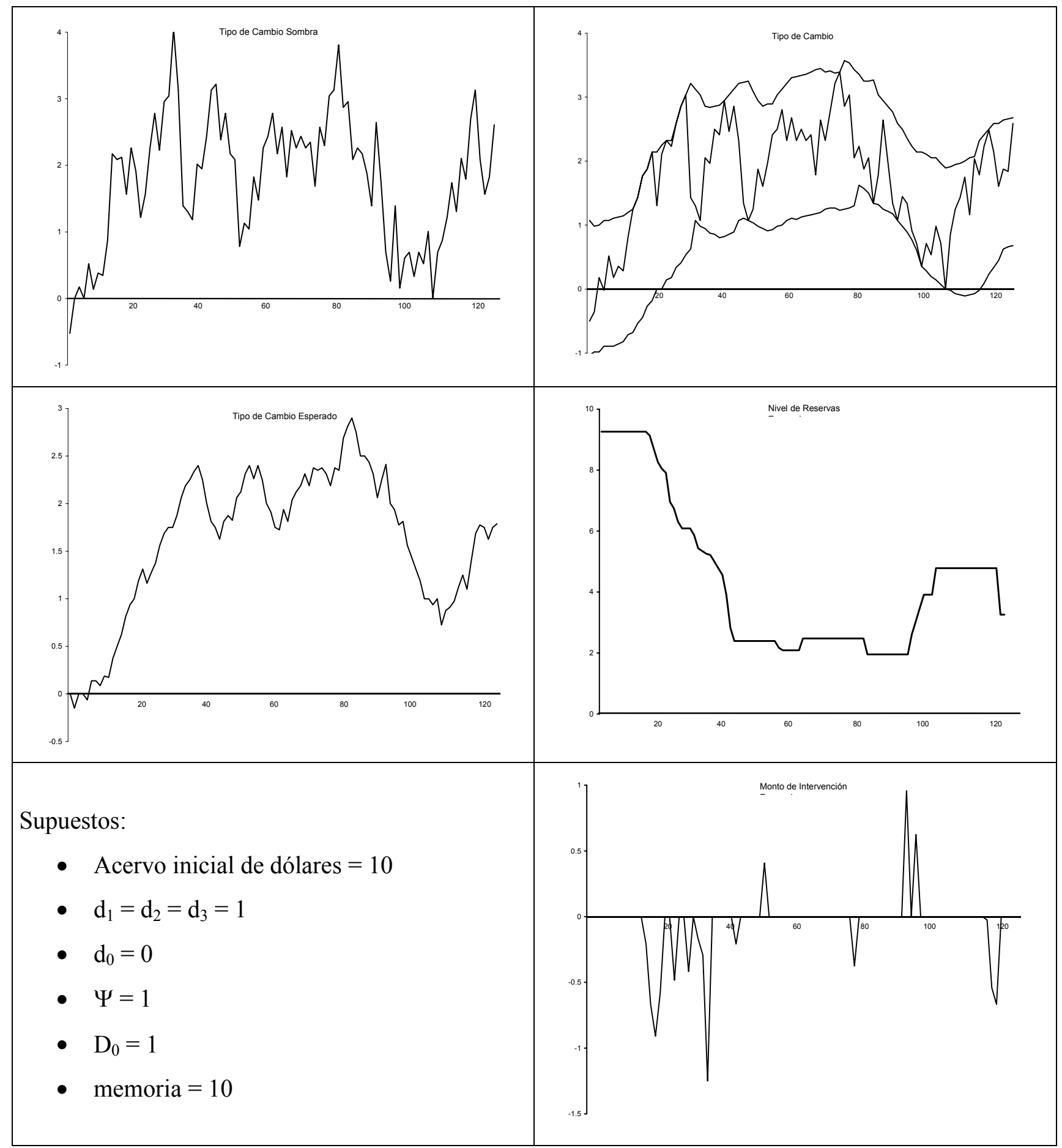




\section{Gráfica 19}

Ejercicio de Simulación del Comportamiento del Mercado de Cambios con Bandas Viscosas Tasas de interés flexibles.

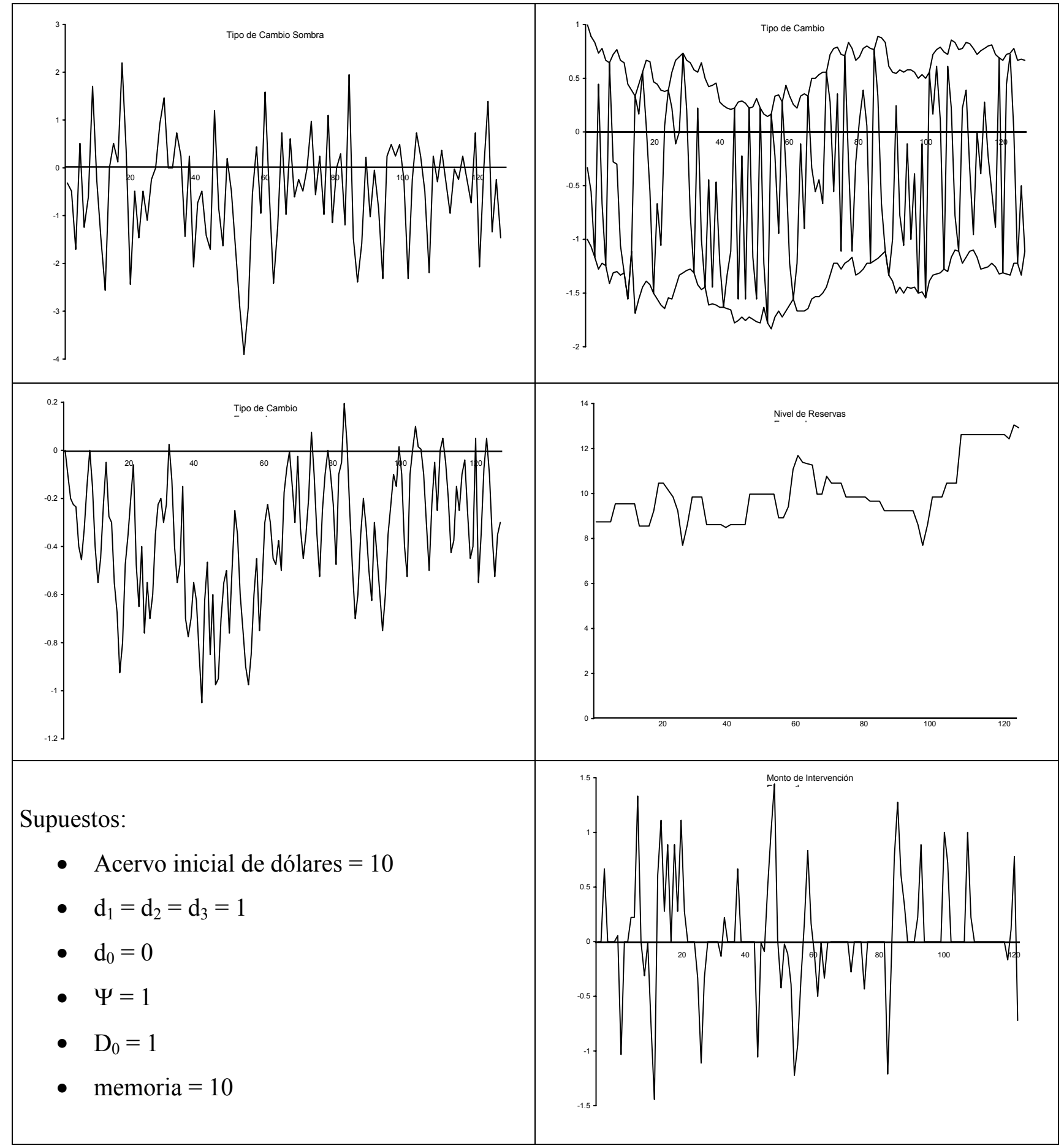




\subsubsection{FACTORES QUE DETERMINAN LA SOSTENIBLIDAD DEL RÉGIMEN CAMBIARIO.}

La última parte de este ejercicio consiste en realizar simulaciones del mercado de cambios para distintas "memorias" y anchos de banda. Las corridas que se reportan contemplan secuencias que terminan al ocurrir el colapso del régimen cambiario o al cumplirse 125 observaciones. Para cada combinación de parámetros del régimen cambiario se hicieron 10 simulaciones, determinándose en cada una de ellas los conceptos que se describen en las columnas de los cuados 1 y 2 (ver Anexo para los detalles sobre la forma en que se hicieron las simulaciones).

Los cuadros 1-a, 1-b y 1-c contienen los resultados para cuando las tasas de interés poco flexibles. Cada uno de estos cuadros tiene dos parte: una suponiendo bandas con credibilidad endógena y otra para el caso de credibilidad exógena. El propósito de esta presentación es de separar el impacto que la elección de la regla monetaria tiene sobre la sostenibilidad del régimen cambiario de la influencia dinámica de formación de expectativas. Así, las columnas agrupadas bajo el rubro $\delta_{\mathrm{t}}=0$ capturan únicamente el efecto de la regla monetaria mientras las demás incorporan también el papel de las expectativas.

Adicionalmente, se hace un análisis de sensibilidad de los resultados a cambios en el valor de los parámetros de la demanda de dólares. Dado que $\mathrm{d}_{0} \mathrm{y}_{3}$ se refieren a conceptos que se mantienen constantes a lo largo del ejercicio (recuérdese que las tasas de interés son fijas), el propósito se logra viendo exclusivamente a la relación entre $\mathrm{d}_{2} \mathrm{y} \mathrm{d}_{1}$. Toda vez que se da a este último el valor de 1 , se reportan simplemente distintos valores de $\mathrm{d}_{2}$. 


\section{Cuadro 1.a}

Sostenibilidad del Régimen Cambiario

Tasas de interés no flexibles

$$
d_{2}=0.1
$$

\begin{tabular}{|c|c|c|c|c|c|c|}
\hline \multicolumn{4}{|c|}{$\begin{array}{c}\text { Bandas con Credibilidad Endógena } \\
\delta_{t}=\left(1-G\left(d_{1} R_{t}+\tau-e_{t}\right)\right) /\left(1-G\left(\tau-e_{t}\right)\right)\end{array}$} & \multicolumn{3}{|c|}{$\begin{array}{l}\text { Bandas con Credibilidad Exógena. } \\
\qquad \delta_{t}=0\end{array}$} \\
\hline \multirow[t]{2}{*}{$\begin{array}{l}\text { Ancho de } \\
\text { la banda en } \\
\text { veces la } \\
\text { desviación } \\
\text { estándar de } \\
\text { la demanda } \\
\text { de dólares }\end{array}$} & $\begin{array}{l}\text { Períodos } \\
\text { en que } \\
\text { tarda en } \\
\text { colapsar el } \\
\text { régimen } \\
\text { cambiario }\end{array}$ & $\begin{array}{l}\text { Tipo de } \\
\text { cambio al } \\
\text { final del } \\
\text { ejercicio }\end{array}$ & $\begin{array}{l}\text { Número de } \\
\text { ejercicios } \\
\text { en los que } \\
\text { el régimen } \\
\text { cambiario } \\
\text { colapsó }\end{array}$ & $\begin{array}{l}\text { Períodos en } \\
\text { que tarda } \\
\text { en colapsar } \\
\text { el régimen } \\
\text { cambiario }\end{array}$ & $\begin{array}{c}\text { Tipo de } \\
\text { cambio al } \\
\text { final del } \\
\text { ejercicio }\end{array}$ & $\begin{array}{l}\text { Número de } \\
\text { ejercicios } \\
\text { en los que } \\
\text { el régimen } \\
\text { cambiario } \\
\text { colapsó }\end{array}$ \\
\hline & Memoria & 25 & & & & \\
\hline 1 & 8.1 & 0.679 & 10 & 7.8 & 0.674 & 10 \\
\hline 2 & 11.7 & 1.378 & 10 & 11.6 & 1.388 & 10 \\
\hline 3 & 23.1 & 2.352 & 10 & 16 & 2.146 & 10 \\
\hline \multirow[t]{2}{*}{4} & 32.3 & 2.247 & 3 & 34.5 & 2.740 & 6 \\
\hline & Memoria & 50 & & & & \\
\hline 1 & 8.2 & 0.608 & 10 & 7.9 & 0.609 & 10 \\
\hline 2 & 10.5 & 1.210 & 10 & 9.6 & 1.207 & 10 \\
\hline 3 & 20.2 & 1.949 & 10 & 21.7 & 1.976 & 10 \\
\hline \multirow[t]{2}{*}{4} & 41.6 & 2.772 & 8 & 44.6 & 2.896 & 10 \\
\hline & Memoria & 75 & & & & \\
\hline 1 & 8 & 0.597 & 10 & 8 & 0.590 & 10 \\
\hline 2 & 10.6 & 1.157 & 10 & 9.9 & 1.154 & 10 \\
\hline 3 & 20.8 & 1.796 & 10 & 18.1 & 1.792 & 10 \\
\hline \multirow[t]{2}{*}{4} & 54.7 & 2.580 & 9 & 35.4 & 2.570 & 10 \\
\hline & Memoria & 100 & & & & \\
\hline 1 & 8 & 0.583 & 10 & 8 & 0.578 & 10 \\
\hline 2 & 8 & 1.110 & 10 & 10.3 & 1.127 & 10 \\
\hline 3 & 17.1 & 1.703 & 10 & 17.8 & 1.715 & 10 \\
\hline 4 & 44.1 & 2.312 & 8 & 31.8 & 2.420 & 10 \\
\hline
\end{tabular}




\section{Cuadro 1.b}

Sostenibilidad del Régimen Cambiario

Tasas de interés no flexibles

$$
d_{2}=0.1
$$

\begin{tabular}{|c|c|c|c|c|c|c|}
\hline \multicolumn{4}{|c|}{$\begin{array}{c}\text { Bandas con Credibilidad Endógena } \\
\delta_{t}=\left(1-G\left(d_{1} R_{t}+\tau-e_{t}\right)\right) /\left(1-G\left(\tau-e_{t}\right)\right)\end{array}$} & \multicolumn{3}{|c|}{$\begin{array}{l}\text { Bandas con Credibilidad Exógena. } \\
\qquad \delta_{t}=0\end{array}$} \\
\hline \multirow[t]{2}{*}{$\begin{array}{l}\text { Ancho de } \\
\text { la banda en } \\
\text { veces la } \\
\text { desviación } \\
\text { estándar de } \\
\text { la demanda } \\
\text { de dólares }\end{array}$} & $\begin{array}{l}\text { Períodos } \\
\text { en que } \\
\text { tarda en c } \\
\text { colapsar el } \\
\text { régimen } \\
\text { cambiario }\end{array}$ & $\begin{array}{l}\text { Tipo de } \\
\text { cambio al } \\
\text { final del } \\
\text { ejercicio }\end{array}$ & $\begin{array}{l}\text { Número de } \\
\text { ejercicios } \\
\text { en los que } \\
\text { el régimen } \\
\text { cambiario } \\
\text { colapsó }\end{array}$ & $\begin{array}{l}\text { Períodos en } \\
\text { que tarda } \\
\text { en colapsar } \\
\text { el régimen } \\
\text { cambiario }\end{array}$ & $\begin{array}{l}\text { Tipo de } \\
\text { cambio al } \\
\text { final del } \\
\text { ejercicio }\end{array}$ & $\begin{array}{l}\text { Número de } \\
\text { ejercicios } \\
\text { en los que } \\
\text { el régimen } \\
\text { cambiario } \\
\text { colapsó }\end{array}$ \\
\hline & Memoria & 25 & & & & \\
\hline 1 & 17.5 & 0.823 & 10 & 14.6 & 0.777 & 10 \\
\hline 2 & 9.6 & 1.164 & 2 & n.s. & 0.777 & 0 \\
\hline 3 & n.s. & 0.398 & 0 & n.s. & 0.319 & 0 \\
\hline \multirow[t]{2}{*}{4} & n.s. & 0.100 & 0 & n.s. & 0.230 & 0 \\
\hline & Memoria & 50 & & & & \\
\hline 1 & 15.4 & 0.678 & 10 & 16.3 & 0.677 & 10 \\
\hline 2 & 48.6 & 1.131 & 5 & 50.3 & 1.401 & 5 \\
\hline 3 & n.s. & 0.604 & 0 & n.s. & 0.867 & 0 \\
\hline \multirow[t]{2}{*}{4} & n.s. & 0.449 & 0 & n.s. & 0.231 & $\underline{0}$ \\
\hline & Memoria & 75 & & & & \\
\hline 1 & 15.6 & 0.629 & 10 & 14.9 & 0.634 & 10 \\
\hline 2 & 51.5 & 1.232 & 7 & 60.5 & 1.451 & 9 \\
\hline 3 & n.s. & 0.458 & 0 & n.s. & 0.499 & 0 \\
\hline \multirow[t]{2}{*}{4} & n.s. & 0.444 & 0 & n.s. & 0.094 & 0 \\
\hline & Memoria & 100 & & & & \\
\hline 1 & 11.6 & 0.601 & 10 & 14.7 & 0.612 & 10 \\
\hline 2 & 78.0 & 1.468 & 9 & 59.8 & 1.383 & 10 \\
\hline 3 & n.s. & 0.826 & 0 & n.s. & 0.144 & 0 \\
\hline 4 & n.s. & 0.212 & 0 & n.s. & 0.327 & 0 \\
\hline
\end{tabular}




\section{Cuadro 1.c}

Sostenibilidad del Régimen Cambiario

Tasas de interés no flexibles

$$
d_{2}=0.1
$$

\begin{tabular}{|c|c|c|c|c|c|c|}
\hline \multicolumn{4}{|c|}{$\begin{array}{c}\text { Bandas con Credibilidad Endógena } \\
\delta_{t}=\left(1-G\left(d_{1} R_{t}+\tau-e_{t}\right)\right) /\left(1-G\left(\tau-e_{t}\right)\right)\end{array}$} & \multicolumn{3}{|c|}{$\begin{array}{l}\text { Bandas con Credibilidad Exógena. } \\
\qquad \delta_{t}=0\end{array}$} \\
\hline \multirow[t]{2}{*}{$\begin{array}{l}\text { Ancho de } \\
\text { la banda en } \\
\text { veces la } \\
\text { desviación } \\
\text { estándar de } \\
\text { la demanda } \\
\text { de dólares }\end{array}$} & $\begin{array}{l}\text { Períodos } \\
\text { en que } \\
\text { tarda en c } \\
\text { colapsar el } \\
\text { régimen } \\
\text { cambiario }\end{array}$ & $\begin{array}{l}\text { Tipo de } \\
\text { cambio al } \\
\text { final del } \\
\text { ejercicio }\end{array}$ & $\begin{array}{l}\text { Número de } \\
\text { ejercicios } \\
\text { en los que } \\
\text { el régimen } \\
\text { cambiario } \\
\text { colapsó }\end{array}$ & $\begin{array}{l}\text { Períodos en } \\
\text { que tarda } \\
\text { en colapsar } \\
\text { el régimen } \\
\text { cambiario }\end{array}$ & $\begin{array}{l}\text { Tipo de } \\
\text { cambio al } \\
\text { final del } \\
\text { ejercicio }\end{array}$ & $\begin{array}{l}\text { Número de } \\
\text { ejercicios } \\
\text { en los que } \\
\text { el régimen } \\
\text { cambiario } \\
\text { colapsó }\end{array}$ \\
\hline & Memoria & 25 & & & & \\
\hline 1 & 68.3 & 0.650 & 3 & 90.0 & 1.059 & 10 \\
\hline 2 & n.s. & 0.222 & 0 & n.s. & 0.027 & 0 \\
\hline 3 & n.s. & 0.240 & 0 & n.s. & 0.362 & 0 \\
\hline \multirow[t]{2}{*}{4} & n.s. & -0.070 & 0 & n.s. & 0.352 & 0 \\
\hline & Memoria & 50 & & & & \\
\hline 1 & 67.3 & 0.959 & 10 & 43.1 & 0.872 & 10 \\
\hline 2 & n.s. & 0.136 & 0 & n.s. & 0.216 & 0 \\
\hline 3 & n.s. & 0.199 & 0 & n.s. & 0.260 & 0 \\
\hline \multirow[t]{2}{*}{4} & n.s. & 0.195 & 0 & n.s. & 0.016 & $\underline{0}$ \\
\hline & Memoria & 75 & & & & \\
\hline 1 & 31.9 & 0.713 & 10 & 39.2 & 0.744 & 10 \\
\hline 2 & n.s. & 0.198 & 0 & n.s. & 0.058 & 0 \\
\hline 3 & n.s. & 0.067 & 0 & n.s. & 0.277 & 0 \\
\hline \multirow[t]{2}{*}{4} & n.s. & 0.062 & 0 & n.s. & -0.037 & 0 \\
\hline & Memoria & 100 & & & & \\
\hline 1 & 32.5 & 0.675 & 10 & 35.1 & 0.674 & 10 \\
\hline 2 & n.s. & 3.301 & 0 & n.s. & 0.344 & 0 \\
\hline 3 & n.s. & 0.287 & 0 & n.s. & 0.296 & 0 \\
\hline 4 & n.s. & -0.012 & 0 & n.s. & 0.001 & 0 \\
\hline
\end{tabular}




\section{a. La Sostenibilidad de la politica cambiaria se asocia directamente con la amplitud de la banda.}

De hecho, para bandas con un ancho equivalente a 3 ó más $\sigma$ no se tienen colapsos cambiarios, en ningún caso.

Para la interpretación de este y los demás resultados es útil apuntar que en el modelo se tienen dos efectos operando en direcciones opuestas. Por un lado lo que podría llamarse "efecto inercia" que actúa en contra de la sostenibilidad del régimen cambiario, y el "efecto credibilidad" que contribuye a estabilizar al tipo de cambio dentro de la banda.

El "efecto inercia" se debe a que cuando la autoridad adopta una regla que implica una base monetaria y/o tasas de interés menos flexibles, el tipo de cambio sombra sigue una caminata al azar lo cual puede implicar desviaciones sustanciales respecto del techo de la banda en un gran número de casos. Por su parte, el "efecto credibilidad" tiene que ver con la forma en que el público ajusta sus expectativas y con ello su demanda de dólares al identificar la presencia de bandas que se perciben sostenibles. Se trata precisamente de la propiedad de "toque suave" mencionada repetidamente en el documento.

Así, para un nivel dado de reservas y tipo de cambio, bandas más anchas serán más anchas serán más creíbles, y por lo tanto, el "efecto credibilidad" tendrá a dominar al "efecto inercia" al punto que el régimen de bandas sea sostenible.

No sobra insistir aquí, por trivial que parezca, que el resultado resalta que no siempre las bandas son sostenibles lo cual no es tema que se considere explícitamente en la literatura teórica de bandas.

\section{b. Los ejercicios confirman que en general las bandas pueden jugar un importante papel} estabilizador del tipo de cambio.

Al contrastar los resultados que se reportan en los distintos escenarios es posible identificar que cuando el "efecto credibilidad" es significativo, se da el círculo virtuoso que va de una banda creíble a un tipo de cambio esperado menos volátil, y de ahí a una paridad observada más estable lo que al final se traduce en menos intervenciones del Instituto Emisor, validando así la credibilidad de la banda. 
Esta conclusión se deriva específicamente de ver que cuando $d_{2}$ toma valores más altos la banda es sostenible en prácticamente todas las iteraciones, mientras que con valores más bajos de $d_{2}$ donde hay muchos casos en los que el régimen cambiario colapsa antes de 125 periodos. Un valor bajo de este parámetro implica que la credibilidad o no de la banda tienen una influencia mínima sobre la demanda de dólares, lo cual hace irrelevante que el Banco Central tenga muchas o pocas reservas. De manera equivalente, este sería el resultado que se obtendría si el público no concede credibilidad alguna al compromiso cambiario independientemente del valor de $d_{2}$.

c. En promedio, mientras más integrados estén los mercados de capitales más sostenibles serán las bandas. Sin embargo, si por algún motivo las reservas caen a niveles que afecten la credibilidad del compromiso cambiario, mientras más integrados estén los mercados más rápido será el colapso del régimen de bandas.

Este resultado sigue inmediatamente de la conclusión anterior puesto que, como se mencionó al inicio de la sección 3, valores más altos de $d_{2}$ se interpretan como un mayor grado de integración en los mercados de capitales.

En cuanto a la rapidez con que colapsa el régimen cambiario podría verse lo que sucede en esquemas de "memoria larga" con valores altos de $d_{2}$ donde el efecto de endogenizar la credibilidad de las bandas se traduce en periodos más cortos de supervivencia del régimen.

d. En la explicación de porqué colapsan los regímenes cambiarios, los resultados sugieren que la selección de política monetaria juega un papel de primer orden mientras que el efecto de endogenizar la credibilidad de las bandas desempeña un rol menos importante.

Esta conclusión resulta de comparar las columnas en las que se reporta el comportamiento de los distintos esquemas cambiarios bajo credibilidad endógena y exógena, y donde las diferencias no son apreciables. De hecho, como se apuntó atrás sólo cuando $d_{2}$ es mayor que la unidad y las bandas se vuelven menos flexibles es que se ve que los colapsos cambiarios ocurren, en promedio, antes de lo que sucede cuando las bandas son plenamente creíbles. 
No obstante este resultado, debe reconocerse que según se vio en los ejemplos de los incisos anteriores al modelar las expectativas del público de esta manera puede entenderse mejor lo que sucede en las últimas etapas de un esquema cambiario, particularmente en lo relativo a la composición de los portafolios del público.

e. Las bandas viscosas de "memoria corta" son apreciablemente más resistentes que las bandas fijas cuando no hay una fuerte integración de los mercados de capitales y/o cuando la credibilidad del público acerca del compromiso cambiario es baja. Cuando la integración es mayor sus ventajas no son apreciables.

A esta conclusión vale la pena añadir tres comentarios. En primer lugar, las bandas viscosas de "memoria corta" sólo muestran un mejor desempeño cuando se trata de bandas de anchura intermedia. En el caso de bandas delgadas la proporción de ejercicios que colapsan es igual que bajo las demás especificaciones.

Segundo, la efectividad de las bandas viscosas cae muy rápidamente al alargarse la memoria. Por ejemplo, no es tan obvio que se obtenga un beneficio importante al acortar la memoria de 100 a 75 períodos.

Tercero, en virtud de que se trata entonces de considerar esquemas con memorias cortas hay que considerar que éstas, por construcción, asimilan la dinámica del proceso subyacente de determinación del tipo de cambio razón por la que terminan generando más incertidumbre de largo plazo. En el límite, esta situación nos estaría llevando a comparar entre la libre flotación y un esquema con bandas anchas, donde en principio el segundo será siempre preferible al primero ya que permite aprovechar parte de los efectos estabilizadores de las bandas en el corto plazo y simultáneamente acota la volatilidad de largo plazo. 


\section{Cuadro 2}

Sostenibilidad del Régimen Cambiario

Tasas de interés flexibles

$$
d_{2}=1.0
$$

\begin{tabular}{|c|c|c|}
\hline \multirow{2}{*}{$\begin{array}{l}\text { Ancho en veces desviación } \\
\text { estándar de los choques de } \\
\text { demanda de dólares }\end{array}$} & $\begin{array}{l}\text { Tipo de cambio al final } \\
\text { del período }\end{array}$ & $\begin{array}{l}\text { Número de ejercicios en los } \\
\text { que el régimen cambiario } \\
\text { colapsó }\end{array}$ \\
\hline & Memoria $=25$ & \\
\hline 1.0 & -0.074 & 0 \\
\hline 2.0 & -0.351 & 0 \\
\hline 3.0 & -0.192 & 0 \\
\hline 4.0 & -0.216 & 0 \\
\hline \multicolumn{3}{|c|}{ Memoria $=50$} \\
\hline 1.0 & 0.110 & 0 \\
\hline 2.0 & 0.202 & 0 \\
\hline 3.0 & -0.163 & 0 \\
\hline 4.0 & -0.301 & 0 \\
\hline \multicolumn{3}{|c|}{ Memoria $=75$} \\
\hline 1.0 & -0.194 & 0 \\
\hline 2.0 & 0.321 & 0 \\
\hline 3.0 & -0.201 & 0 \\
\hline 4.0 & -0.250 & 0 \\
\hline \multicolumn{3}{|c|}{ Memoria $=100$} \\
\hline 1.0 & -0.121 & 0 \\
\hline 2.0 & -0.167 & 0 \\
\hline 3.0 & -0.119 & 0 \\
\hline 4.0 & -0.045 & 0 \\
\hline
\end{tabular}

Por su parte, el cuadro 2 muestra lo que sucede cuando las tasas de interés son flexibles.

a. Una política monetaria orientada primordialmente al control del crédito interno permite sostener prácticamente cualquier régimen de bandas, fijas o "viscosas". Por eso, a fin de aprovechar en lo posible la propiedad de “toque suave”, la política más adecuada sería la de bandas angostas. 
b. Toda vez que en este contexto las bandas viscosas pueden implicar realineaciones frecuentes con los inconvenientes que resalta Werner (1994), además de una banda estrecha estos ejercicios apuntan hacia la conveniencia de que ésta sea de "memoria” larga.

\section{CONSIDERACIONES DE POLÍTICA ECONÓMICA}

\section{1 ¿ES POSIBLE INSTRUMENTAR UNA POLÍTICA MONETARIA PARA ESTABILIZAR EFICAZ Y SOSTENIDAMENTE EL TIPO DE CAMBIO, BAJO UN RÉGIMEN DE TIPO DE CAMBIO FIJO, O DE BANDAS CAMBIARIAS?}

A pesar de experiencias internacionales recientes que pueden conducir a pensar lo contrario, la respuesta es sí aunque ello no signifique que sea sencillo lograrlo. Las reflexiones que se presentaron a lo largo del documento sugieren que los factores que contribuyen a la sostenibilidad del régimen cambiario no sólo se encuentra en lo que hagan las autoridades en tiempos normales, sino en lo que el público percibe será la manera en que operarán aquéllas cuando el tipo de cambio se acerque al techo de la banda y/o las reservas internacionales disminuyan. Así, además de ser muy importante que se siga una política monetaria y fiscal restrictiva como sería esterilizar las entradas de capitales, vigilar cuidadosamente la evolución de los agregados monetarios de acuerdo con el comportamiento de la demanda por dinero y contar con un superávit presupuestal, también lo es que el público considere que la voluntad de las autoridades por mantener la disciplina seguirá vigente cuando éstas se vean forzadas a intervenir en el mercado de cambios para defender la cotización de la moneda local. De no ser así bastaría con que los participantes en el mercado piensen, por ejemplo, que las autoridades monetarias se sentirán forzadas por una u otra razón a esterilizar parte del efecto de su intervención para que se incremente la demanda de moneda extranjera incrementando así las posibilidades de rompimiento del compromiso cambiario.

No obstante lo anterior, esta afirmación debe matizarse considerando el entorno institucional en que se toman las decisiones. Concretamente, aunque en este documento se subrayaron las ventajas de aplicar una política donde las tasas de interés respondan con rapidez a choques exógenos, por otro lado no se abundó sobre lo que significa asumir los costos de dicha política. Específicamente, si al elevar las tasas se afecta muy seriamente la salud del sistema financiero de tal suerte que las pérdidas de los bancos comerciales terminen monetizándose, los argumentos sobre la credibilidad y estabilidad de las bandas 
se debilitan, siendo quizá un análisis más adecuado el presentado por Flood y Garber (1984b) y Obsfeld (1986) en cuanto a la posibilidad de tener equilibrios múltiples.

Además, para apoyar el compromiso de la política monetaria con la estabilidad de precios las autoridades deben contar con los instrumentos que permitan operar de manera eficaz dicha política. Por ejemplo, los bancos centrales pueden influir sobre el comportamiento de los niveles de crédito ya sea a través de fijar límites específicos al acceso que tengan los bancos a la ventanilla de descuento, o bien mediante el ajuste de las tasas de interés a las cuales las instituciones financieras disponen de crédito primario. Aunque en términos generales ambas opciones pudieran verse como equivalentes, esta característica se vuelve menos obvia en épocas de duda sobre la estabilidad del tipo de cambio, puesto que aun si las tasas de interés a las que el Instituto Central ofrece recursos alcanzaran rápidamente niveles muy elevados todavía deberá pasar algún tiempo antes de que estas acciones se traduzcan en la contracción deseada del crédito. Por lo tanto, en virtud de que el mecanismo de transmisión de la política monetaria a vía de tasas de interés tiende a ser más lento, la falta de mecanismos para el control inmediato sobre la liquidez del Banco Central podría traducir, de facto, un a política monetaria no acomodaticia en una de esterilización parcial de las salidas de capitales con consecuencias desfavorables sobre la percepción del público y sobre la dinámica del tipo de cambio.

\section{2 ¿QUÉ FACTORES INSITUCIONALES DE LA POLÍTICA MONETARIA PUEDEN CONTRIBUIR DE MANERA A FORTALECER SU CREDIBILIDAD Y, CON ELLO, A ELEVAR SU CAPACIDFAD PARA ESTABIIZAR EL TIPO DE CAMBIO?}

Ciertamente la estrecha relación entre el comportamiento de los bancos centrales y las acciones del público incide de manera determinante en su capacidad para propiciar la estabilidad de precios, del tipo de cambio y las tasas de interés. Por esta razón al revisar el desempeño de esquemas de tipo de cambio fijo y de flotación dentro de las bandas, vistos ambos como mecanismos para establecer horizontes más o menos predecibles a precios y con mayor flexibilidad y por lo tanto contribuir a la sostenibilidad del régimen cambiario, los esquemas de bandas no han sido capaces de disuadir los ataques ni de responder satisfactoriamente ante ellos. En este documento se ve que si bien las bandas pueden tener un efecto estabilizador importante, las características específicas del régimen cambiario no son triviales para el resultado final. Por ejemplo, cuando las autoridades consideran que la volatilidad excesiva de las tasas de interés no es deseable una solución adecuada es una banda suficientemente ancha como para 
absorber únicamente "choques" de gran magnitud. Optar por bandas "viscosas" de corta memoria hace que el esquema sea sostenible pero la incertidumbre de largo plazo del tipo de cambio puede ser demasiado grande, más aún si las reservas son escasas.

En contraste, cuando la economía está en condiciones de absorber tasas de interés más volátiles y en consecuencia las autoridades sujetan su programa monetario al control del crédito interno, no sólo resulta sostenible sino altamente deseable establecer un régimen de bandas estrechas para estabilizar el tipo de cambio.

\section{3 ¿CÓMO AFECTA EL RÉGIMEN CAMBIARIO LA CREDIBILIDAD DE LA POLÍTICA MONETARIA?}

Finalmente, para cerrar el círculo sobre la relación entre la política monetaria y cambiaria debe considerarse que ésta también se da yendo de las características del régimen cambiario a la credibilidad y sostenibilidad de la política monetaria.

Este tema está íntimamente vinculado con la discusión vinculado con la discusión sobre las ventajas de reglas monetarias versus discrecionalidad de la política de crédito. Si se acepta el hecho de que la predictibilidad de las acciones del Banco Central permite que el público se beneficie de la menor incertidumbre, es de esperarse que una política monetaria creíble orientada a alcanzar metas específicas de inflación o crédito interno será capaz de lograr su objetivo sin necesidad de recurrir persistentemente a tasas de interés elevadas que puedan dañar la planta productiva y el empleo. Sin embargo, también es sabido que en la medida en que los bancos centrales no incurran en elevados costos para desviarse al menos temporalmente de su objetivo monetario, éste difícilmente será alcanzable, cuando el público actúe como si anticipara una política monetaria laxa en el futuro.

Una posible solución a este dilema viene de la perseverancia, y con ello, de la reputación que las autoridades pudieran ir construyendo a través del tiempo respecto de la seriedad de sus propósitos. Sin embargo, cuando la autonomía de los bancos centrales es relativamente reciente o cuando en contexto macroeconómico del que se parte es de inestabilidad, la credibilidad de la política monetaria puede apuntalarse mediante la adopción de compromisos, cuyo incumplimiento se percibiera de tal manera costoso por parte del público, que de hecho funcionaran como garantía de la intención del Banco 
Central de cumplir con sus metas. Un ejemplo de esto sería un paquete que incluya acuerdos entre los gobiernos de economías pequeñas y abiertas con instituciones financieras internacionales, un régimen de intervención sin esterilización en el mercado de cambios y en un régimen de bandas estrechas, fijas o "viscosas".

Un ejemplo extremo de este tipo de compromisos es el establecimiento de Juntas de Emisión (Currency Boards) o Uniones Monetarias, a través de las cuales el objetivo cambiario y la regla monetaria son definidos con toda transparencia en leyes, y en casos hasta en la Constitución o Tratados Internacionales, de tal manera que la posibilidad de modificarlos implique asumir un elevado costo político. Cuando la situación del sistema financiero es sólida con esquemas como estos suelen alcanzarse rápidamente los objetivos de estabilización de las tasas de interés y precios, si bien se transfiere al sector real la carga del ajuste de choques exógenos tanto transitorios como permanentes. 


\section{BIBLIOGRAFÍA}

P.R. Agénor, J.S.: Bhandari y R.P. Flood, "Speculative Attacks and Models of Balance of Payments Crises", IMF Staff Papers, June 1992, 39, 355-394.

Bertola, G. y R. Caballero. “Target Zones and Realignment”, American Economic Review, 1992, 82, 3, 520-536.

K. Blackburn y M. Sola, "Speculative Currency Attacks and Balance of Payments Crises", Journal of Economic Surveys, 1993, 7, 119-144.

H. Blanco y P.M. Garber, "Recurrent Devaluation and Speculative Attacks on the Mexican Peso", Journal of Political Economy, 1986, 94, 148-166.

Chen, Z. y A. Giovannini. "The Determinants of Realignment Expectations under the EMS: Some Empirical Regularities", NBER Working Paper Series, marzo 1993, 4291.

Eichengreen, B., C. Rose y C. Wyplosz. "Speculative Attacks on Pagged Exchange Rates: An Empirical Exploration with Special Reference to the European Monetary System", documento presentado en la coferencia "Monetary Policy in a Changing Financial Environment", CEPR/Federal Reserve Bank of San Francisco, marzo 1995.

R.P. Flood y P.M. Garber, "Collapsing Exchange Rate Regimes: Some Linear Examples”, Journal of International Economics, 1984a, 18, 1-13.

, “Gold Monetization and Gold Discipline”, Journal of Political Economy, 1984b, 92, 90107.

P. Krugman, “A Model of Balance of Payments Crises", Journal of Money, Credit and Banking, agosto, 1979, 11, 311-25.

, "Target Zones and Exchange Rate Dynamics", NBER Working Paper Series, enero 1988, No. 2481. 
M. Obstfeld, "Rational and self-fulfilling Balance of Payments Crises", American Economic Review, marzo 1986, 86, 72-81.

Schwartz, Moisés. "Exchange Rate Bands and Monetary Policy: The Case of Mexico", Economía Mexicana, segundo semester 1994, III-2, 287-317.

Werner, A. "Essays on Exchange Rate Target Zones and Stabilization Policies", mayo 1994, Tesis Doctoral Inédita, MIT. 


\section{ANEXO. RUTINA UTILIZADA EN LAS SIMULACIONES.}

Los ejercicios de simulación para este documento se llevaron a cabo en Matemática 2.2.2. para Power Macintosh. A continuación se presenta la lista de instrucciones par los dos escenarios de política monetaria. Cada una de ellas tomó aproximadamente 4.5 horas en completarse en una Power Macintosh 7100/66.

\section{A.1. CASO DE TASAS DE INTERÉS POCO FLEXIBLES}

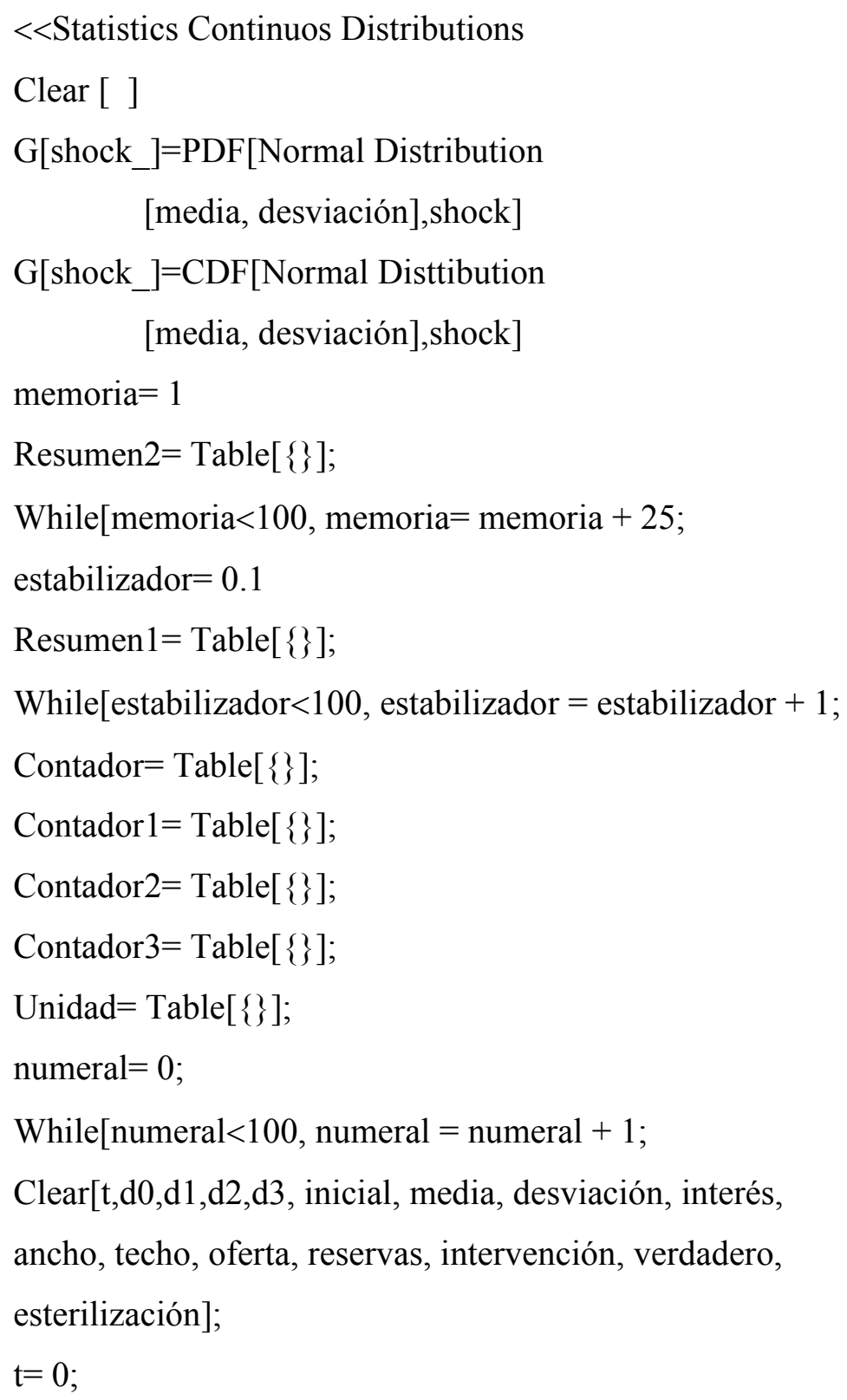


$\mathrm{d} 0=0$;

$\mathrm{d} 1=1$;

$\mathrm{d} 2=1$;

$\mathrm{d} 3=0$;

inicial $=10$;

media $=0$;

desviación $=1$;

interés $=10$;

exrate $=0$

ancho= estabilizador* desviación;

techo $=$ exrate +0.5 ancho;

oferta $=$ inicial $/ 10$;

reservas $=(9 / 10)$ inicial;

intervención $=0$;

verdadero $=0$;

esterilización $=1$;

sumador $=0$

aleatorio $=0$;

While [reservas $>0 \& \& \mathrm{t}<125$, reservas $=$ reservas

intervención;

techo $=($ techo $*($ memoria -1$)+($ exrate +0.5 ancho $)) /$ memoria;

delta[exrate_reservas_] $=[1-\mathrm{G}[$ reservas +techo-exrate $]] /[1-\mathrm{G}[$ techo-exrate $]]$;

esperado $=\mathrm{N}[$ exrate $+(1-$ delta[exrate,reservas $])$

(Integrate[shock g[shock],

\{shock,(techo-extrate-ancho),(techo-extrate)\}]/

$(\mathrm{G}[$ techo-exrate]-G[techo-extrate-ancho]))+

(delta[exrate,reservas])

(Integrate[shock g[shock],

\{shock,(techo-ancho-exrate), Infinity\}]/

(1-G[techo-ancho-exrate]))];

verdadero $=\mathrm{N}[(1 /(\mathrm{d} 1+\mathrm{d} 2))$

(oferta-

d0-d2 esperado + 
d3 interes +

Random[NormalDistribution[media,desviación]])

];

observado $=\operatorname{Max}[$ (techo-ancho $)$,

Min[verdadero,techo];

Intervención $=\mathrm{d} 1($ If $[$ verdadero $>$ techo,

(verdadero-techo),

(-esterilizacion)

If[verdadero

$<$ (techo-ancho),

(verdadero-techo+ancho),0]

]):

sumador $=$ sumador + If[reservas $==(9 / 10)$ inicial $, 1,0]$;

exrate $=\operatorname{Max}[($ techo-ancho $)$,

Min[verdadero,techo]];

oferta $=\mathrm{N}[$ inicial-reservas $]$;

$\mathrm{t}=\mathrm{t}+1$;

;

AppendTo[Contador, $\{$ t,sumador $\}]$;

AppendTo[Contador 1,r]

AppendTo[Contador2,sumador];

AppendTo[Contador3,exrate];

AppendTo[Unidad,1];

Sobrevida $=$ Contador 1 -Contador 2 ;

Survival1 $=($ Unidad.Contador 1$) /$ numeral;

Choques $=($ Unidad.Contador 2$) /$ numeral;

Survival2=Survival1-Choques;

Tipo $=($ Unidad.Contador3 $) /$ numeral

];

AppendTo[Resumen1,\{Survival1,Survival2,Tipo $\}$;

];

AppendTo[Resumen2, $\{$ Resumen 1$\}]$;

] 


\section{A.2 CASO DE TASAS DE INTERÉS FLEXIBLES}

$<<$ StatisticsContinuosDistributions

Clear [ ]

G[shock_] $=$ PDF[Normal Distribution

[media, desviación],shock]

G[shock_] $=$ CDF[Normal Disttibution

[media, desviación],shock]

memoria $=1$

Resumen $2=\operatorname{Table}[\{\}]$;

While $[$ memoria $<100$, memoria $=$ memoria +25 ;

estabilizador $=0.1$

Resumen $1=$ Table $[\{\}]$;

While[estabilizador $<100$, estabilizador $=$ estabilizador +1 ;

Contador $=$ Table $[\{\}]$;

Contador $1=$ Table $[\{\}]$;

Contador2= Table $[\{\}]$;

Contador $3=$ Table $[\{\}]$;

Unidad $=$ Table $[\{\}]$

numeral $=0$;

While $[$ numeral $<100$, numeral $=$ numeral +1 ;

Clear $[\mathrm{t}, \mathrm{d} 0, \mathrm{~d} 1, \mathrm{~d} 2, \mathrm{~d} 3$, inicial, media, desviación, interés, ancho, techo, oferta, reservas, intervención, verdadero, esterilización];

$\mathrm{t}=0$;

$\mathrm{d} 0=0$;

$\mathrm{d} 1=1$;

$\mathrm{d} 2=1$;

$\mathrm{d} 3=0$;

inicial $=10$;

media $=0$;

desviación $=1$; 


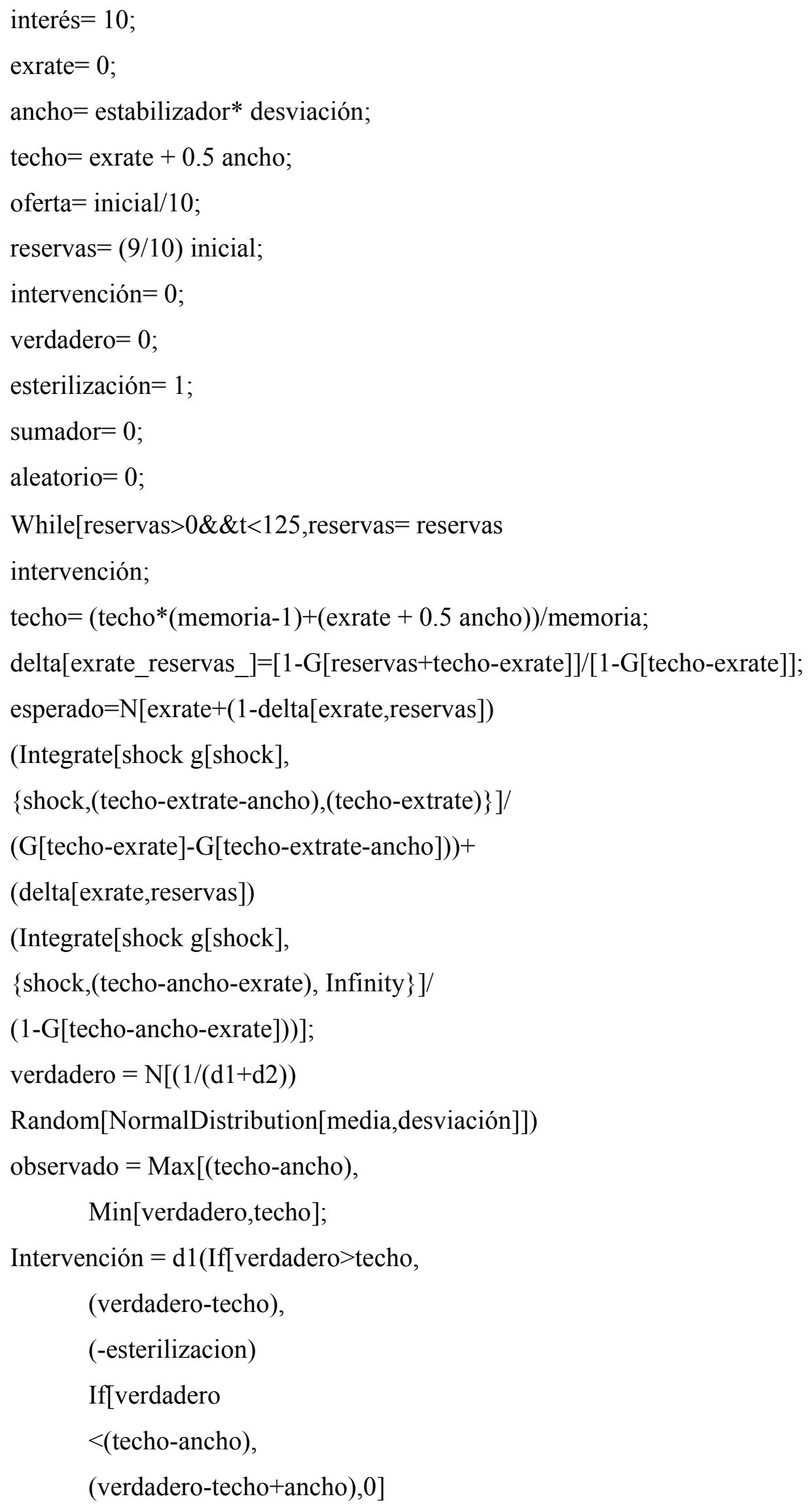


]):

exrate $=\operatorname{Max}[($ techo-ancho $)$,

Min[verdadero,techo]];

oferta $=\mathrm{N}[$ inicial-reservas $]$;

$\mathrm{t}=\mathrm{t}+1$;

];

AppendTo[Contador, $\{\mathrm{t}$,sumador $\}]$;

AppendTo[Contador1,r]

AppendTo[Contador2,sumador];

AppendTo[Contador3,exrate];

AppendTo[Unidad,1];

Sobrevida=Contador1-Contador2;

Survival1 $=($ Unidad.Contador1 $) /$ numeral;

Choques $=($ Unidad.Contador2) $/$ numeral;

Survival2=Survival1-Choques;

Tipo $=($ Unidad.Contador3) $/$ numeral

];

AppendTo[Resumen1,\{Survival1,Survival2,Tipo $\}$;

];

AppendTo[Resumen2, \{Resumen1\}];

] 